Review

\title{
Synthesis and Use of Stable Isotope Enriched Retinals in the Field of Vitamin A
}

\author{
Prativa B.S. Dawadi and Johan Lugtenburg * \\ Leiden Institute of Chemistry, Leiden University, P.O. Box 9502, 2300 RA, Leiden, The Netherlands; \\ E-Mail: p.b.s.dawadi@gmail.com (P.B.S.D.)
}

* Author to whom correspondence should be addressed; E-Mail: lugtenbu@chem.leidenuniv.nl.

Received: 15 January 2010; in revised form: 18 February 2010 / Accepted: 2 March 2010 /

Published: 15 March 2010

\begin{abstract}
The role of vitamin A and its metabolites in the life processes starting with the historical background and its up to date information is discussed in the introduction. Also the role of 11Z-retinal in vision and retinoic acid in the biological processes is elucidated. The essential role of isotopically enriched systems in the progress of vision research, nutrition research etc. is discussed. In part B industrial commercial syntheses of vitamin A by the two leading companies Hoffmann-La Roche (now DSM) and BASF are discussed. The knowledge obtained via these pioneering syntheses has been essential for the further synthetic efforts in vitamin A field by other scientific groups. The rest of the paper is devoted to the synthetic efforts of the Leiden group that gives an access to the preparation of site directed high level isotope enrichment in retinals. First the synthesis of the retinals with deuterium incorporation in the conjugated side chain is reviewed. Then, ${ }^{13} \mathrm{C}$-labeled retinals are discussed. This is followed by the discussion of a convergent synthetic scheme that allows a rational access to prepare any isotopomer of retinals. The schemes that provide access to prepare any possible isotope enriched chemically modified systems are discussed. Finally, nor-retinals and bridged retinals that give access to a whole (as yet incomplete) library of possible isotopomers are reviewed.
\end{abstract}

Keywords: wittig reaction; nitrile chemistry; retinals; deuterium; ${ }^{13} \mathrm{C}$-incorporation 


\section{Contents}

Part A Introduction

Part B Technical Syntheses

1. Hoffmann-La Roche (now DSM)

2. BASF

Part C Site-Directed Highly Stable Isotope Enriched Retinals

1. Deuterium Labeled Retinals

1.1. Incorporation of deuterium at positions 18 and 19 of retinal 1: Preparation of $11 Z-\left[18-\mathrm{D}_{3}\right]$-retinal and $11 Z-\left[19-\mathrm{D}_{3}\right]$-retinal

1.2. Incorporation of deuterium at positions 10, 11, 12, 14 and 20 of retinal 1: Preparation of all-E [10D]-retinal, all-E [11-D]-retinal, all-E [12-D]-retinal, all-E [11,12-D $]$-retinal, all-E [10,11-- 2 ]retinal, all-E $\left[14,20,20,20-\mathrm{D}_{4}\right]$-retinal

1.3. Incorporation of deuterium at positions 14, 15 and 20 of retinal 1: Preparation of all-E [14-D]retinal, all-E [15-D]-retinal, all-E [14,15-D 2$]$-retinal and all-E [20,20,20-D 3 -retinal

2. ${ }^{13} \mathrm{C}$-Labeled Retinals

2.1. Incorporation of ${ }^{13} \mathrm{C}$ at positions 14 and 15 of retinal 1: Preparation of $\left[14-{ }^{13} \mathrm{C}\right]$-retinal, $\left[15-{ }^{13} \mathrm{C}\right]-$ retinal and $\left[14,15-{ }^{13} \mathrm{C}_{2}\right]$-retinal

2.2. Incorporation of ${ }^{13} \mathrm{C}$ in the six membered ring of retinal 1 : Preparation of $\left[1-{ }^{13} \mathrm{C}\right]-,\left[2-{ }^{13} \mathrm{C}\right]-,[1,3-$ $\left.{ }^{13} \mathrm{C}_{2}\right]$ - and $\left[1,2,3-{ }^{13} \mathrm{C}_{3}\right]-,\left[3-{ }^{13} \mathrm{C}\right]-,\left[4-{ }^{13} \mathrm{C}\right]-,\left[5-{ }^{13} \mathrm{C}\right]-,\left[4,5-{ }^{13} \mathrm{C}_{2}\right]-,\left[6-{ }^{13} \mathrm{C}\right]-,\left[7-{ }^{13} \mathrm{C}\right]-$, and $\left[18-{ }^{13} \mathrm{C}\right]-$ retinal

2.3. Incorporation of ${ }^{13} \mathrm{C}$ at all positions of retinal 1: Preparation of $\left[\mathrm{U}_{-}{ }^{13} \mathrm{C}\right]$-retinal

3. Isotope Enriched Chemically Modified Retinals

3.1. Preparation of (11Z)-3,4-didehydroretinal, (3R)-(11Z)-3-hydroxyretinal and (4R)-(11Z)-4hydroxyretinal

3.2. Preparation of 10-methylretinal, 10-methylthioretinal, 10-iodoretinal and 19-fluororetinal

3.3. Preparation of 11-methylretinal and 12-methylretinal

3.4. Preparation of 9-demethyl-9-haloretinals and 13-demethyl-13-haloretinals

4. $\alpha$-Retinals via $\alpha$-Ionone

4.1. 9-Demethyl-9-halo- $\alpha$-retinals, 9-substituted $\alpha$-retinals, 9-demethyl $\alpha$-retinal, 19 , 19 -ethano- $\alpha$ retinal, 19,19- dimethyl $\alpha$-retinal and 12- and 14-halo substituted $\alpha$-retinals

5. Nor-Retinals

5.1. 16,17,18-Trinor-retinal, 16,17-dinor-retinal and 16-nor-retinal

6. Bridged and Demethyl Retinals

6.1. DL-8,16-Methanoretinal, 8,18-methanoretinal, $(R)$-5-demethyl-8,16-methanoretinal, 1,5didemethyl-8,16-methanoretinal, 1,1-didemethyl-8,18-methanoretinal, 1,1-didemethyl-18didehydro-8,18-methanoretinal

6.2. 11,19-10,20-Dimethanoretinal, 10,20-methanoretinal, 13-demethyl-10,12-ethanoretinal, 13demethyl-12,14-ethanoretinal, 13-demethyl-10,12-propanoretinal and 13-demethyl-12,14propanoretinal

6.3. 13-Demethyl-10,14-thiaretinal and 11,14-bridged 13-demethyl retinals 
6.4. 9-Demethyl retinal, 13-demethyl retinal and 9,13-didemethyl retinal Conclusion

\section{Part A. Introduction}

In 1909 a fat soluble principal obtained from egg yolk, which proved essential for life was described [1]. Shortly afterwards, the same factor was found in butter, egg yolk extract and cod liver oil [2]. In 1919 it was observed that carotenoids have the same growth promoting activity as the factor described above, which was later called vitamin $\mathrm{A}_{1}$ (even later retinol) [3]. Of the thirteen natural occurring carotenoids that enter our body via food, four compounds have intact a $\beta$-carotene-half. They are $\alpha$-carotene, $\beta$-carotene, $\gamma$-carotene and $\beta$-cryptoxanthin. These are enzymatically converted in the intestinal wall into vitamin $A_{1}$ [4]. $\beta$-Carotene is the best source of vitamin $A$ because it is symmetrical and the oxidative splitting of the 15,15'-double bond gives two vitamin A molecules (see Scheme 1) [5].

Scheme 1. Enzymatic conversions in the human (animal body); $\mathbf{1}=$ all- $E$ retinal, $\mathbf{2}=$ all- $E$ retinol (vitamin $A_{1}$ ), $\mathbf{3}=$ all- $E$ retinoic acid. The IUPAC numbering is given in retinal $\mathbf{1}$. Chemically all- $E$ retinal 1 can be reduced by $\mathrm{NaBH}_{4}$ into all- $E$ retinol 2 . All- $E$ retinol 2 can be oxidized by $\mathrm{MnO}_{2}$ to all- $E$ retinal 1. All- $E$ retinal 1 can be oxidized by $A_{2} \mathrm{O}$ into all- $E$ retinoic acid $\mathbf{3}$ and all- $E$ retinoic acid $\mathbf{3}$ can be reduced by $\mathrm{LiAlH}_{4}$ into all- $E$ retinol $\mathbf{2}$.

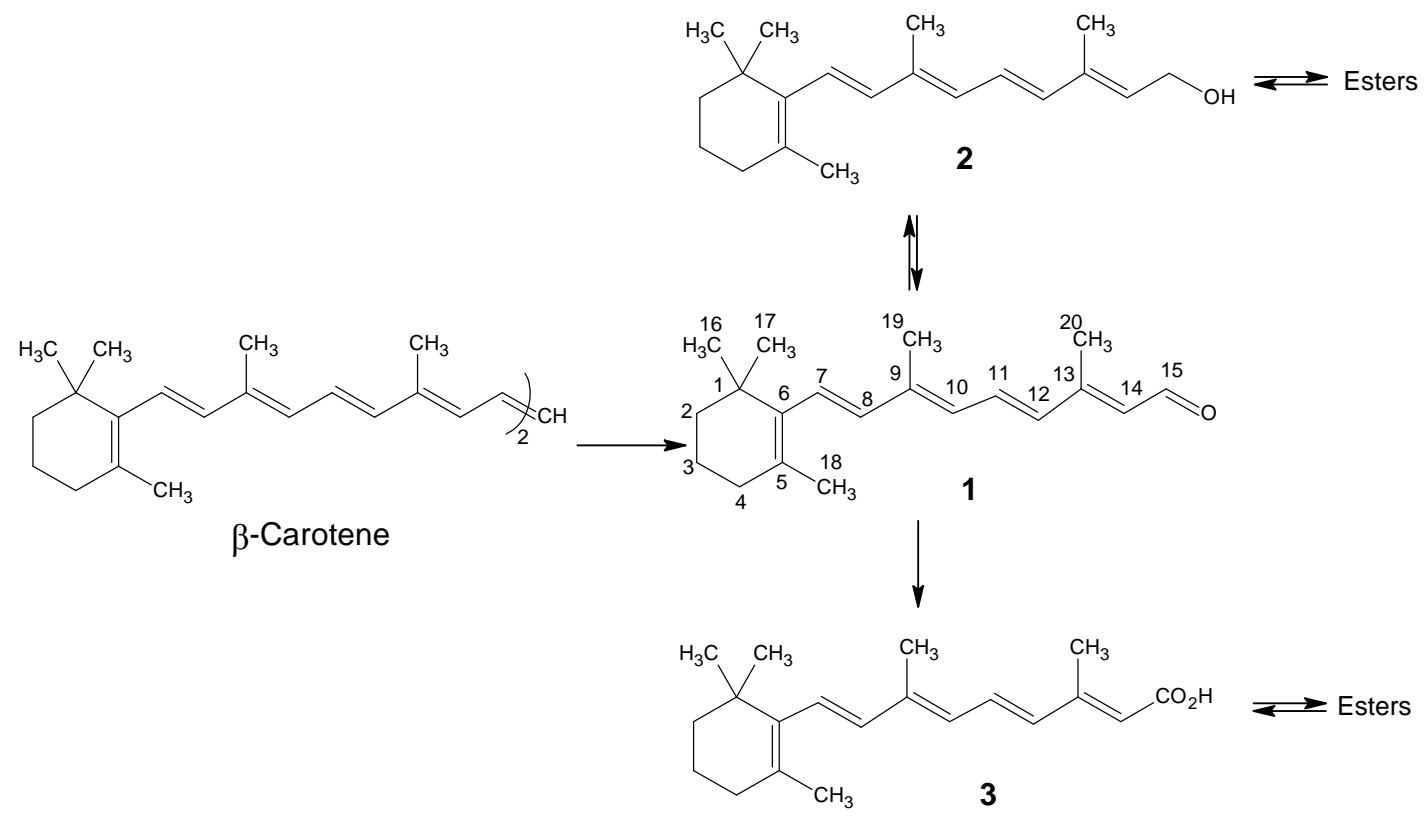

Interestingly, carotene biosynthesis takes place in the chloroplast of the plant cells, cyanobacteria and algae via the methyl erythritol phosphate pathway distinct from the mevalonic acid pathway for all other isoprenoids [6]. In 1931 the structures of $\beta$-carotene and vitamin $A_{1}$ (retinol 2) were published $[7,8]$. These structures are depicted in Scheme 1. Somewhat earlier the bioconversion of $\beta$-carotene into retinol had been described [9]. In 1944 the release of vitamin A aldehyde (retinal 1) after the irradiation of the retina was observed [10]. The structure of the chromophore in visual pigments could be established via synthetic 11Z-retinal [11]. The visual pigments of the three phyla of animals 
(vertebrates, mollusks and anthropods) are membrane-bound photoreceptors that have 11Z-retinal as a chromophore in the active site [12]. Only in the case of amphibians and fresh water fish (11Z)-3,4-didehydroretinal (also known as vitamin $\mathrm{A}_{2}$ aldehyde) forms the chromophore. In some flies and insects the chromophore is (3R)-(11Z)-3-hydroxyretinal and in squid it is (4R)-(11Z)-4hydroxyretinal $[13,14]$.

The visual pigments belong to the important class of G-protein coupled receptors [15]. The $11 Z$-chromophore acts as the inverse agonist. Light converts it to the all- $E$ structure which acts as a full agonist. In the human retina there are 120 million rods and some 6 million cones. The rods have $\lambda_{\max } 498 \mathrm{~nm}$ and they are active in scotopic vision. The three different types of cones serve photopic vision and their $\lambda_{\max }$ values are $425 \mathrm{~nm}, 530 \mathrm{~nm}$ and $560 \mathrm{~nm}$, respectively. The visual pigments are located in the outer segments of the rod and cone cells. In the case of humans (and other vertebrates) at the end of the visual cycle all- $E$ retinal is released from the light-activated pigment, which is reduced to all- $E$ retinol. All- $E$ retinol is transported to the pigment epithelium layer where it is enzymatically converted to 11Z-retinol, oxidized to $11 Z$-retinal and recombined with the apoprotein opsin in the outer segments to reform rhodopsin [16]. Besides being members of the important class of G-protein coupled receptors, visual pigments also belong to the retinal proteins which even occur in single cell organisms. In these organisms all- $E$ retinal serves as an essential light-absorbing chromophore.

Retinoic acid $\mathbf{3}$ is an important morphogen that regulates many biological development processes in the embryo, the development of the central nervous system etc. Retinoic acid $\mathbf{3}$ is the agonist for the nuclear retinoic acid receptor that occurs in subforms- $\alpha, \beta$ and $\gamma$. They activate the transcription of target genes [17]. Also, a distinct type of retinoid $X$ receptor with a similar activity has been discovered. The principal ligand for this receptor is 9Z-retinoic acid. These receptors (retinoic acid receptor and retinoid $\mathrm{X}$ receptor) form heterodimers and interact with other receptors. The status of the research in this field up to 1994 is discussed in the literature [17].

Since then new and important retinol metabolites in the growth control of $\beta$-lymphocytes have been reported. They are (14R)-14-hydroxy-4,14-retro-retinol 4, all- $E(13 R, 14 R)$-13,14-dihydroxyretinol 4a, 4,5-didehydro-15,5-retro-deoxyretinol (also known as anhydroretinol) 5, and all-E (13S,14R)-13,14dihydroxyretinol (a minor diastereoisomer) [18-20]. Their structures are depicted in Figure 1.

Anhydroretinol 5 reversibly inhibits the action of retinol 2 and (14R)-14-hydroxy-4,14-retro-retinol 4. This inhibitory function is probably due to the competition of two structurally closely related compounds for the same receptor [19]. These systems are messenger molecules that act independently from the retinoic acid receptors. Recently, the enzymatic formation of (13R)-13,14-dihydroretinol 6 has been described [21,22]. It has been observed that (13R)-13,14-dihydroretinol 6 is enzymatically converted into (13R)-13,14-dihydroretinoic acid 7. This molecule activates the retinoic acid receptor/retinoid X receptor heterodimers but not the retinoid X receptor homodimers [23]. The study of retinol and its metabolites and their various important biological functions has been a very fruitful active research area and is steadily yielding new important findings. 
Figure 1. The structures of (14R)-14-hydroxy-4,14-retro-retinol 4, (13R,14R)-13,14dihydroxyretinol 4a, 4,5-didehydro-15,5-retro-deoxyretinol or anhydroretinol 5, (13R)13,14-dihydroretinol 6 and (13R)-13,14-dihydroretinoic acid 7. The IUPAC numbering is given in the structure 4 .

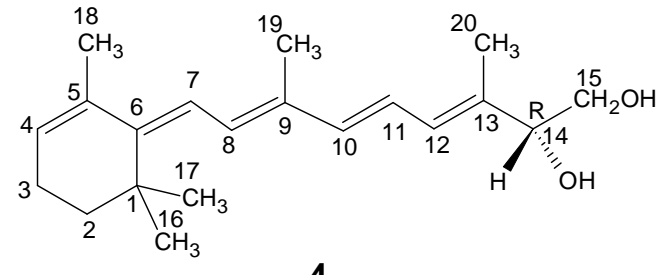

4<smiles>C=CC(C)=CC=CC(C)=CC=C1C(C)=CCCC1(C)C</smiles>

5<smiles>CC1=C(/C=C/C(C)=C/C=C/[C@@](C)(O)[C@@H](O)CO)C(C)(C)CCC1</smiles>

$4 a$<smiles>CC1=C(/C=C/C(C)=C/C=C/[C@H](C)CCO)C(C)(C)CCC1</smiles>

6<smiles>CC1=C(/C=C/C(C)=C/C=C/[C@H](C)CC(=O)O)C(C)(C)CCC1</smiles>

Sufficient retinol or retinol equivalents have to be available via food to maintain the essential functions discussed before. It has been proposed that the adequate retinol amount for men and women is $700 \mu \mathrm{g}$ and $600 \mu \mathrm{g}$, respectively as a daily dose [24]. Also, the retinol needs in infants, children, the elderly, pregnant and lactating women have been quantified [24]. At what intake level retinol toxicity is effective, especially in early pregnancy is not known.

When the human body doesn't get sufficient amounts of retinol, the first observed effect is the impairment of scotopic vision leading to the night blindness. The next effect with lower levels of retinol is perturbation of the maintenance and maturation of the corneal epithelium. In many cases a so called Bitot's spot is formed on the cornea. The molar concentration of retinol in human tears has been reported to be $0.5 \times 10^{-7}$ [25]. The transport of retinoids in tears takes place via the human tear protein lipocalin [26]. Insufficient amount of retinol eventually leads to further severe health effects until the death of the organism. In 1994 it was estimated that 1.5 million children between 6-15 years of age became blind and an additional 0.5 million new cases of childhood blindness occur annually [27]. Approximately $70 \%$ of these cases are the result of severe vitamin A deficiency [28]. A later estimate is that 250 million preschool age children, particularly in developing countries are compromised by vitamin A deficiency. About 3 million children annually are likely to exhibit clinical eye signs of 
deficiency and between 250,000 and 500,000 may needlessly become blind [29]. Subclinical vitamin A status is difficult to access quantitatively through field surveys.

The need for sufficient vitamin A supplies started the search for commercial total synthesis by industrial firms. The first commercial supplies of vitamin A were started when Unilever decided in 1950 to use synthetic vitamin A from Hoffmann-La Roche to enrich their margarine [30]. In 1973 BASF reported that they had realized a factory that produced 600 tons of vitamin A per year via Wittig chemistry [31]. In 1991 it was reported that the three companies (Hoffmann-La Roche, BASF and Rhône-Poulenc) that were marketing vitamin A at that time produced about 3000 tons of vitamin A in total each year. At that moment they sold $1 \mathrm{~kg}$ of vitamin A for an amount of US \$ 120 [32]. About $80 \%$ of the vitamin $\mathrm{A}$ is used in the animal feed for the intensive animal husbandry and $20 \%$ is used as human food supplement. This means that for the people in the developed world that can read these lines practically all the vitamin in the chromophore of a visual pigment is derived from industrial sources.

The main commercial vitamin A producing companies are Hoffmann-La Roche and BASF. The knowledge obtained via these pioneering syntheses has been essential for the further synthetic efforts in the vitamin A field. The four other commercial syntheses that are not used any more are reviewed in the literature [30,33]. Lately, the fine-chemical department of Hoffmann-La Roche including the vitamin A production has been taken over by DSM.

In order to follow the biochemical conversions in the body isotopically labeled systems are essential. This type of study was pioneered by Schoenheimer with stable isotope labeled macronutrients [34]. At that time for the micronutrient retinol this approach would not have worked because of the low sensistivity of the detection techniques for the stable isotopes. However, the radioactive isotopes ${ }^{3} \mathrm{H}$ and ${ }^{14} \mathrm{C}$ became available in ever higher specific activities. The preparation of ${ }^{3} \mathrm{H}$ and ${ }^{14} \mathrm{C}$ labeled retinoids has been reviewed [35].

In the mean time the analytical techniques have greatly improved in sensitivity such that site directed stable isotope retinoids with high isotope incorporation at at least 3 positions $\{(10,19,19,19$ ${ }^{2} \mathrm{H}$ )-retinyl acetate $\}$ have become very favorable [36]. The separation properties may even change upon introduction of a number of isotopes, as in the case of deuterium enriched $\beta$-carotene; octadeutero $\beta$-carotene can be separated from natural abundance $\beta$-carotene with HPLC techniques [37].

In order to minimize isotope effects in multiisotope enriched systems the use of multi ${ }^{13} \mathrm{C}$-enriched system is very useful. The mass ratio of carbon is 13/12 and the isotopes are situated in the molecular skeleton. For these reasons ${ }^{13} \mathrm{C}$ labeled systems are used recently as a reference in nutritional studies [38-40].

The ultimate goal in nutritional research, namely the individual establishment of the nutritional status in real time, is now in sight. The structural and functional research in visual pigments is another area where the access to a whole library of stable isotopes $\left({ }^{2} \mathrm{H},{ }^{13} \mathrm{C}\right)$ with a high level of site-directed incorporation is essential.

In visual pigments the chromophore (retinal) is a small part in the centre of a membrane protein, where the photochemical conversion is effected within $200 \mathrm{fs}$ leading to a primary photoproduct that has a life time in the eye for about $10 \mathrm{~ns}$ and it is metastable below $-140{ }^{\circ} \mathrm{C}$. Resonance Raman spectroscopy gives vibrational information about the chromophore without interference of the rest of the protein due to the fact that some vibrations that are coupled to the electronic transitions may be 
intensified up to a million fold, compared to those not coupled to the electronic transitions. The presence of isotopes doesn't change the molecular force field, only changes in frequencies and in coupling of vibrations occur upon introduction of heavy isotopes. The use of a set of isotopomers is essential to a full vibrational analysis and translation of this information in the structures of the starting system, the photoproduct and the various intermediates in the photocycle [41].

The other vibrational method is Fourier Transform IR difference spectroscopy, in this way the changes in vibrations between two states can be observed [42]. For example, deuterated retinal was incorporated into ppr (pharaonis phoborhodopsin), and the C-D vibrations of deuterated retinal at position 14 was examined at $2200-2300 \mathrm{~cm}^{-1}$ [43]. On the other hand, incorporation of ${ }^{13} \mathrm{C}$ allows the use of ${ }^{13} \mathrm{C}$ NMR. Rhodopsin with fully ${ }^{13} \mathrm{C}$-enriched chromophore gives the chemical shift values of each carbon atom in the chromophore. The values of the $\mathrm{sp}^{2}$ carbons are very useful because they supply information on the electronic charges in the chromophore [44]. Using double quantum NMR techniques of the chromophore selective for next neighbour ${ }^{13} \mathrm{C}$ pairs at low temperatures, the chemical shift values of most of the $\mathrm{sp}^{2}$ atoms of the primary photo intermediate bathorhodopsin have been measured [45]. Torsion angles and carbon-carbon bond length in proteins can be accurately measured as well $[46,47]$. Specific interactions with amino acid residues in the active site next to the retinal chromophore can be detected [48].

The primary structures of all human proteins are now available with the completion of the human genome project [49]. In the post-genomic era in a very rapid process, the total genomes of a plethora of other organisms are also becoming available in addition to mutants that lead to malfunctioning or nonfunctioning proteins leading to genetic diseases. Furthermore, efficient procedures are available via biotechnology to obtain the proteins using these genetic codes [50,51]. The fundamental challenge now is to study the chemical processes of these proteins involving (bio)macromolecules without perturbation in the native states at the atomic level in time scales ranging from femtoseconds up to days [52].

Nature provides us with the ultimate probe via stable isotopes. Isotopes combine nearly identical chemical properties with different physical properties [53]. Study of a system with site-directed isotope labeling with a high incorporation level allows the determination of the whole force field via vibrational techniques such as FT infrared spectroscopy and (Resonance) Raman spectroscopy based on the difference in isotopic mass [41,54,55]. These techniques probe, for instance, the electron density in chemical bonds of the isotope labeled molecule. Another spectroscopic method is solid-state magic angle spinning (MAS) NMR spectroscopy, which probes the electron density at the atoms. This technique detects electronic charges at the atoms, protonation states, and configurations and conformations around bonds of the stable isotopically labeled molecule [44,56]. Comparison of the structural parameters obtained via these techniques for intermediate I and intermediate $\mathrm{I}+1$ in the biochemical process of the studied system provides functional information, that is, changes in protonation states, bond lengths, configuration, and conformation around bonds on the time scale involved [41,57]. When sufficient structural and functional information at the atomic level of the native form has been obtained, a whole new dimension can be attained by studying in a similar fashion systems with mutations in the protein chain and systems with rationally designed chemical changes in the cofactors $[44,57]$. These studies will lead to an even deeper understanding of the biochemical process. The implementation of the above-mentioned program has now utmost urgency. Without this 
program the now increasingly available genetic information in the post-genomic era cannot be translated into the required structural and functional information that will lead to the expected quantum jump in the understanding of the various processes in human (animal) health and diseases and the expected rational approach to treat these diseases. The access to a full number of possible site-directed stable isotopically enriched building blocks (amino acids and cofactors) up to the uniformly labeled systems is a "condition sine qua non" for the proposed structural and functional investigations. All uniformly isotopically labeled amino acids and several cofactors are available via photosynthetic organisms that are grown in media containing ${ }^{13} \mathrm{CO}_{2}$ and ${ }^{15} \mathrm{NH}_{3}$ [58]. To start the above-mentioned program, access to building blocks with isotope labels at each defined atomic position and combination of positions up to the uniformly labeled form is required. The only way to obtain access to the whole cassette of desired isotopomers is a modular synthetic approach such that one synthetic scheme can give in a rational way the required building block as a cassette of all isotopomers. This approach may seem Herculean; however, only 20 different amino acids and a limited number of cofactors are required. The synthesis of these cassettes has to be based on a limited number of commercially available highly enriched stable isotopically labeled starting materials.

The selection of $\left[\mathrm{U}_{-}^{13} \mathrm{C}_{20}\right.$ ]-labeled all- $E$ retinal and all its isotopomers in the new modular approach is based on the fact that retinal and retinoids play a very important role in many life processes [59-61]. In addition, structural and functional studies with isotope sensitive techniques have already been initiated in the field of rhodopsin $[44,56,62,63]$.

Rhodopsin serves as the paradigm for the superfamily of seven transmembrane helix G-protein coupled receptors (GPCRs) [64]. The GPCRs mediate a broad array of physiologically and pharmacologically important signal transduction processes. GPCRs trigger a wide variety of physiological processes that involve signaling by neurotransmitters, hormones, and neuropeptides [65]. Consequently, GPCRs are the major pharmaceutical targets for pharmacological intervention in human (and veterinary) pathology. In rhodopsin the photoreactive ligand is 11Z-retinal that is covalently bound in the interior of the protein via a protonated Schiff base linkage with lysine residue 296 to form the retinylidene chromophore [66].

The full vibrational analysis of the chromophore of rhodopsin and its photoproduct bathorhodopsin has been reported via about 70 isotopomers [55,67]. Furthermore, the chemical shift values of the $\mathrm{sp}^{2}$ carbons in the tail end of the chromophore have been reported $[44,62]$. The distances between $\mathrm{C}_{10}-\mathrm{C}_{20}$ and $\mathrm{C}_{11}-\mathrm{C}_{20}$ could be determined with very high precision $(0.1 \AA)$ via the 1 -D rotational resonance solid-state ${ }^{13} \mathrm{C}$ NMR technique [56]. From these distance measurements the precise chromophore structure could be derived. The molecular torsional angle around a bond in the chromophore labeled with two ${ }^{13} \mathrm{C}$ isotopes could be directly established via this method [68]. Furthermore, the ultrahighfield solid-state MAS NMR study on the $\left[8,9,10,11,12,13,14,15,19,20-{ }^{13} \mathrm{C}_{10}\right]-11-Z$-retinylidene chromophore in its natural lipid membrane environment has been published [44]. This study showed that the use of multispin labeling in combination with 2-D solid-state MAS NMR correlation spectroscopy improves the relative accuracy of the shift measurements in solids. This allows the electronic structure of the retinylidene chromophore to be analyzed at high levels of understanding: (1) by specifying the interactions between the ${ }^{13} \mathrm{C}$-labeled ligand and the G-protein coupled receptor target and (2) by making an assessment of the various factors contributing to the charge distribution in the chromophore. Nowadays, information of much higher quality about 20 carbon atoms can be obtained 
in one short experimental session that thus far has taken a decade to collect [69]. Nevertheless, these results are obtained via studies of the almost unlimited supply of bovine rhodopsin from cattle eyes. However, cone pigments of man and other animals and the various opsins with site-directed mutations have to be obtained via biotechnological expression systems, which implies that now the availability is the limiting factor [51,70]. Recently, the solid-state ${ }^{15} \mathrm{~N}$ MAS NMR study of rod visual pigment rhodopsin in which $99 \%{ }^{15} \mathrm{~N}$ enriched $\left[\alpha, \varepsilon^{-15} \mathrm{~N}_{2}\right]$-L-lysine is incorporated by using the baculovirus/Sf9 cell expression system has been published [63].

In this paper the synthetic routes adopted by DSM and BASF for the production of vitamin A will be discussed in part $\mathrm{B}$. Then, the synthesis of deuterated retinol with $\mathrm{CD}$ or $\mathrm{CD}_{3}$ groups on the conjugated chain and the strategies to obtain retinals enriched with ${ }^{13} \mathrm{C}$ on a limited number of positions (for the accessibility of many mono- and $\mathrm{di}^{13}{ }^{13} \mathrm{C}$-enriched retinals) will be discussed in part $\mathrm{C}$. Finally, the schemes that allow preparation of any ${ }^{13} \mathrm{C}$ isotopomer will be reviewed. This will be complemented by chemically modified retinals that are now accessible in any isotopically labeled form. The paper closes with the discussion of chemically modified retinals where access to any isotopomer has not yet been attained. The synthetic retinoids by other groups have been extensively reviewed in literature [68-71]. Retinoids can occur in 16 different geometric isomers. The access to the whole set of geometric isomer has been described [71-74].

\section{Part B. Technical Syntheses}

\section{Hoffmann-La Roche, DSM}

In Scheme 2 the synthetic route is depicted to show the Hoffmann-La Roche, DSM technical synthesis of vitamin A from the simple starting materials that lead to $\beta$-ionone 17, an important intermediate in the commercial production of vitamin A $[33,75,76]$. For a technical process to be commercially viable a synthetic scheme has to be developed that starts with simple available starting materials from petrochemical sources.

Acetone $\mathbf{8}$ is coupled with the acetylide anion (prepared by the reaction of acetylene and Grignard reagent) to give 2-methylbut-3-yn-2-ol which is reduced by Lindlar catalyst (selective hydrogenation) to 2-methylbut-3-en-2-ol 9. This product is coupled with 2-methoxyprop-1-ene 10 under acid catalyzed condition to give propenyl ether 11 [77]. An oxy-Cope rearrangement of the propenyl ether 11 gave 6-methylhep-5-en-2-one 12. Further coupling of the product 12 with the acetylide anion gave 3,7-dimethyloct-6-en-1-yn-3-ol 13. Treatment of the product 13 with 2-methoxyprop-1-ene 10 upon acid catalyzed condition afforded 3,7-dimethyl-3-(prop-1-en-2-yloxy)oct-6-en-1-yne 14, which

underwent a Cope rearrangement to give the allenic ketone 15. Compound $\mathbf{1 5}$ is isomerized to pseudoionone 16 [78]. Pseudoionone 16 is cyclized into $\beta$-ionone 17 in the presence of sulphuric acid. In this reaction protonation takes place at carbon 2 to give tertiary carbenium ion at carbon 1 . Carboncarbon bond formation takes place to give a six membered ring by nucleophilic attack of carbon 6 at the carbon 1 (the tertiary carbenium ion) and further work-up afforded $\beta$-ionone 17. 
Scheme 2. The technical conversion of acetone $\mathbf{8}$ and acetylene into $\beta$-ionone $\mathbf{1 7}$.<smiles>C#CC#CC(C)(C)O</smiles>

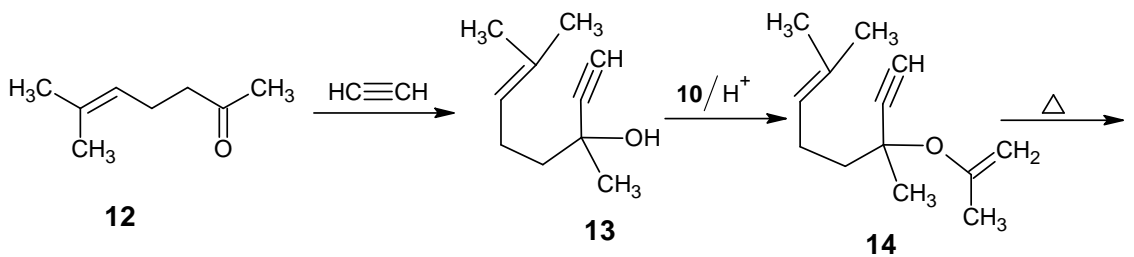

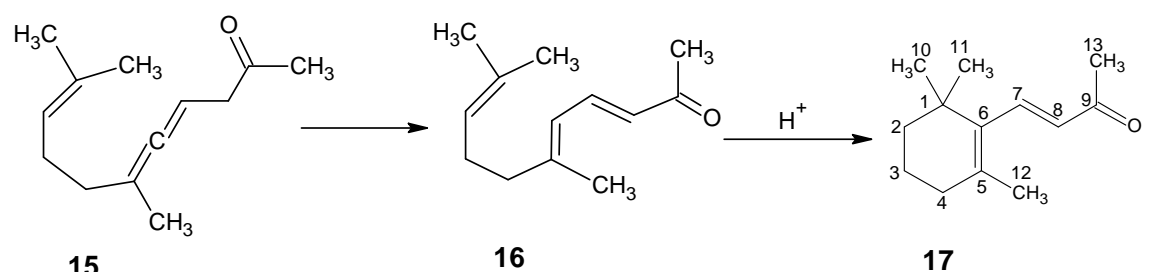

The reactions depicted in Scheme 3 are used for the one carbon chain extension of $\beta$-ionone 17 into the $\beta$ - $\mathrm{C}_{14}$ aldehyde \{2-methyl-4-(2',6',6'-trimethylcyclohex-1'-en-1'-yl)but-2-en-1-al\} 21. A Darzens condensation of 17 with ethyl chloroacetate 18 gave the glycidic ester 19. A base induced saponification of the product $\mathbf{1 9}$ followed by an acid catalyzed epoxy ring opening of the product $\mathbf{2 0}$ and expulsion of $\mathrm{CO}_{2}$ gave the $\beta-\mathrm{C}_{14}$ aldehyde $\mathbf{2 1}$.

Scheme 3. The technical conversion of $\beta$-ionone $\mathbf{1 7}$ into $\beta-\mathrm{C}_{14}$ aldehyde 21.<smiles>CCOC(=O)CCl</smiles><smiles>CC(C=O)=CCC1=C(C)CCCC1(C)C</smiles>

21

The synthetic route depicted in Scheme 4 is used to prepare (2Z)-3-methylpent-2-en-4-yn-1-ol 24. Methyl vinyl ketone 22 is treated with the acetylide anion to form 3-methylpent-4-en-1-yn-3-ol 23. Acid catalyzed rearrangement gave a mixture of (E/Z)-3-methylpent-2-en-4-yn-1-ol 24. Via distillation (2Z)-3-methylpent-2-en-4-yn-1-ol 24 is isolated in pure form. Treatment of ( $Z$ )-enynol 24 with two equivalents of Grignard reagent gave the dianion of $\mathbf{2 4}$ which is coupled with $\beta-\mathrm{C}_{14}$ aldehyde $\mathbf{2 1}$ to give the diol 25 with full vitamin A skeleton. Subsequent Lindlar reduction gave the cis-diol product which is selectively acetylated on the primary hydroxyl function to give the acetate derivative $\mathbf{2 6}$. 
Scheme 4. The preparation of (2Z/2E)-3-methylpent-2-en-4-yn-1-ol 24, coupling of 24 (Zisomer) with $\beta-C_{14}$ aldehyde 21 to give the product 25 and final conversion of the product 25 into all- $E$ retinyl acetate 27.<smiles>C#CC(C)(O)C(C)(C#C)C=C</smiles>

22

23

$(Z)-24$
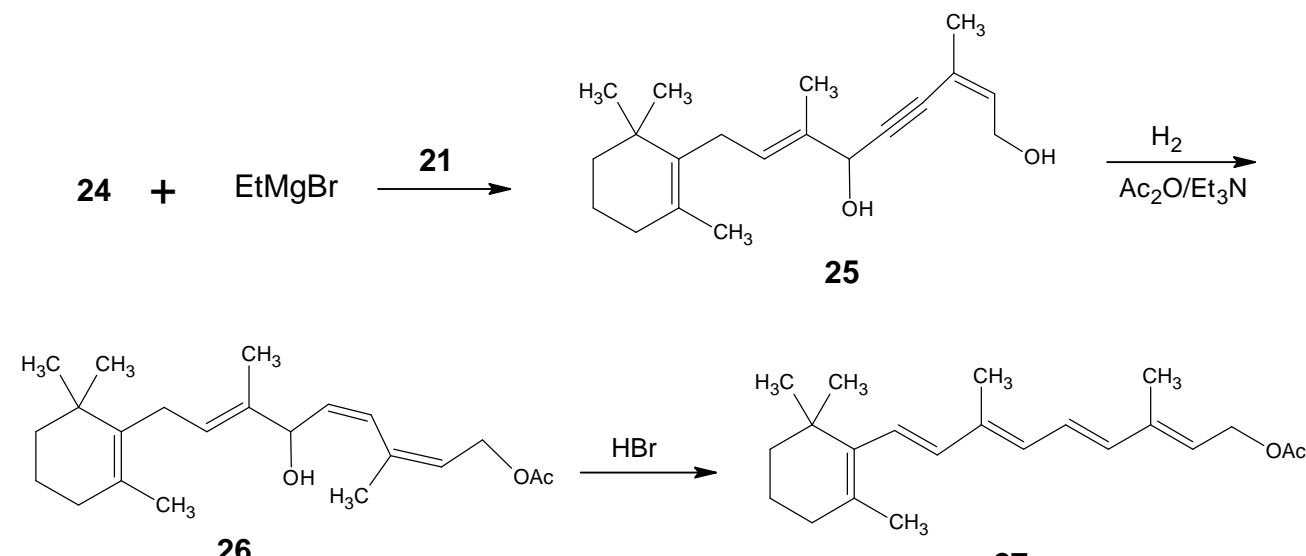

27

Acid catalyzed elimination of the hydroxyl group from carbon 10 of the product $\mathbf{2 6}$ led to a heptatrienyl cation encompassing the $\mathrm{sp}^{2}$ atoms from 8 to 14 . In this fully conjugated system the bond order of each carbon-carbon bond is 1.5 leading to dynamic $E / Z$ isomerization resulting in the most stable fully extended system. Subsequent loss of a proton from carbon 7 gave retinyl acetate 27 in the all- $E$ form in high yield. For information about carbenium ions in the retinoid field see literature [79]. Stronger acid will lead to the protonation at carbon 14 in vitamin A acetate (retinyl acetate) to form a conjugate carbenium ion that will lose a proton from carbon 4 in the ring to form retro-vitamin A acetate (this is the compound $\mathbf{4}$ in Figure 1 without the hydroxyl group at carbon 14).

Similarly, the absence of acetyl protection in the product $\mathbf{2 6}$ will give anhydroretinol $\mathbf{5}$ via elimination of two molecules of water. It is remarkable that the mild acid treatment of the product $\mathbf{2 6}$ on large scale leads to the required retinyl acetate $\mathbf{2 7}$ in high yield without appreciable retro-vitamin A formation. In this technical process Grignard reagents are used on a large scale, for example batches containing $500 \mathrm{~kg}$ of magnesium are used; as a result a great amount of magnesium salt is obtained as a waste. Many steps need only small amount of Pd and acid as a catalyst to minimize the formation of waste product.

\section{BASF}

The technical synthesis of vitamin A developed by BASF starts with the reactions depicted in Schemes 5 and 6 [80-82]. Acid catalyzed reaction of isobutene and formaldehyde gave 3-methylbut-3en-1-ol. Pd catalyzed isomerization converted it into the allylic alcohol $\mathbf{2 8}$ and $\mathrm{Ag}$ catalyzed oxidation gave 3-methylbut-2-en-1-al 29. Products 28 and 29 under azeotropic condition in the presence of nitric acid formed an acetal which eliminated one molecule of $\mathbf{2 8}$ at higher temperatures. The intermediate 
enol ether underwent oxy-Cope rearrangement to give the citral 31. Pseudoionone 16 is obtained by an aldol condensation of citral $\mathbf{3 1}$ with acetone $\mathbf{8}$. The product $\mathbf{1 6}$ is cyclized in the presence of an acid to give the $\beta$-ionone 17. The acid catalyzed conversion of $\mathbf{1 6}$ to $\mathbf{1 7}$ has been discussed in Scheme 2.

Scheme 5. The conversion of isobutene and formaldehyde into $\beta$-ionone 17 via citral $\mathbf{3 1}$.
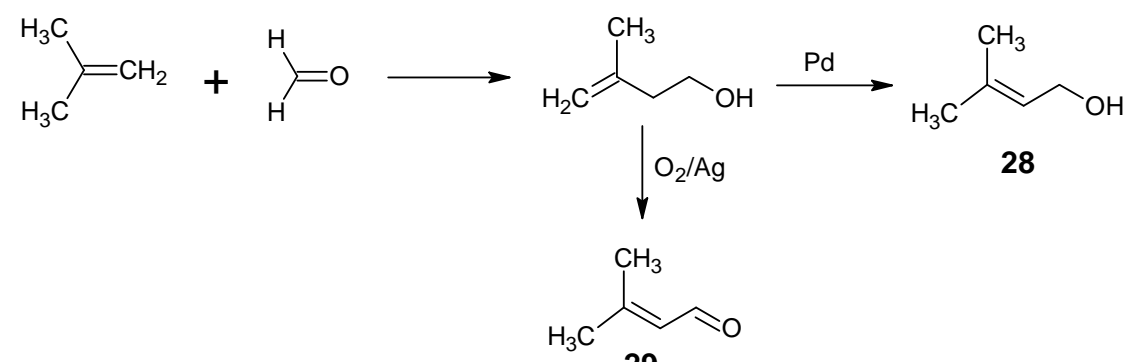

29<smiles>CC=CCOC(C=C(C)C)OCC=C(C)C</smiles><smiles>[C+]OCC=C(C)C</smiles>

30

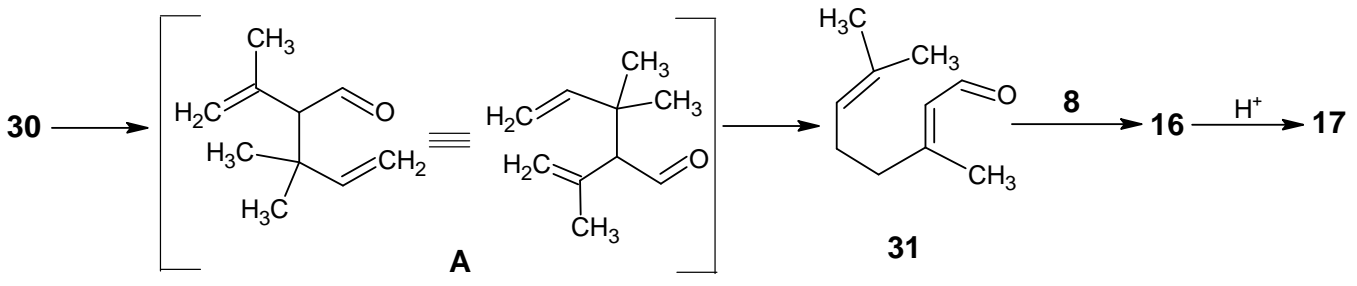

In Scheme 6 the conversion of $\beta$-ionone $\mathbf{1 7}$ into vitamin $\mathrm{A}$ acetate $\mathbf{2 7}$ is depicted. Reaction of $\beta$-ionone 17 with the acetylide anion and subsequent Lindlar reduction gave the vinyl $\beta$-ionol 32 . Treatment of 32 with $\mathrm{HBr}$ in the presence of triphenylphosphine gave all- $E$ conjugate carbenium ion (as has been discussed before). The presence of the soft base triphenylphosphine attacks preferentially at the position 11 to form the all- $E$ [2-( $\beta$-ionylidene)ethyl]triphenylphosphonium bromide 33 [83]. Triphenylphosphine is prepared in an industrial scale by reacting $\mathrm{PCl}_{3}$ (obtained by the reaction of phosphorous and chlorine) and phenylsodium (obtained by the reaction of phenyl chloride and sodium).

4-Acetoxy 2-methylbut-2-en-1-al 35 is the required $\mathrm{C}_{5}$ building block for the preparation of vitamin A acetate 27. Oxirane is treated with acetic acid in the presence of catalytic Ag and air leading to 2-acetoxy ethanal 34. Product 34 underwent an aldol condensation with propanal to give all- $E$ 4-acetoxy-2-methylbut-2-en-1-al 35. Treatment of $\mathbf{3 3}$ with methanolate gave an ylide which is coupled with all-E 35 to afford retinyl acetate $27(70 \%$ all- $E$ and $30 \% 11 Z)$. This means that during the coupling the geometric integrity of the bonds is maintained. Only the new carbon-carbon double bond (C11-C12) is formed both in the predominant $E$ and in the minor 11Z-isomer. The latter can easily be converted into the all- $E$ form. Later in the literature the use of 1,2-epoxybutane as a pseudo base in Wittig reactions has been described [84]. In this case the bromine anion attacks the epoxy ring to form an alcoholate transiently which removes the proton from the phosphonium salt. In this method the Wittig condensation is carried out under very mild conditions. 
Scheme 6. Preparation of [2-( $\beta$-ionylidene)ethyl]triphenylphosphonium bromide $\mathbf{3 3}$ and all-E 4-acetoxy-2-methyl-but-2-en-1-al $\mathbf{3 5}$ and the final HWE coupling of $\mathbf{3 3}$ and $\mathbf{3 5}$ into 27 (70\% all- $E$ retinyl acetate and 30\% 11Z-retinyl acetate).

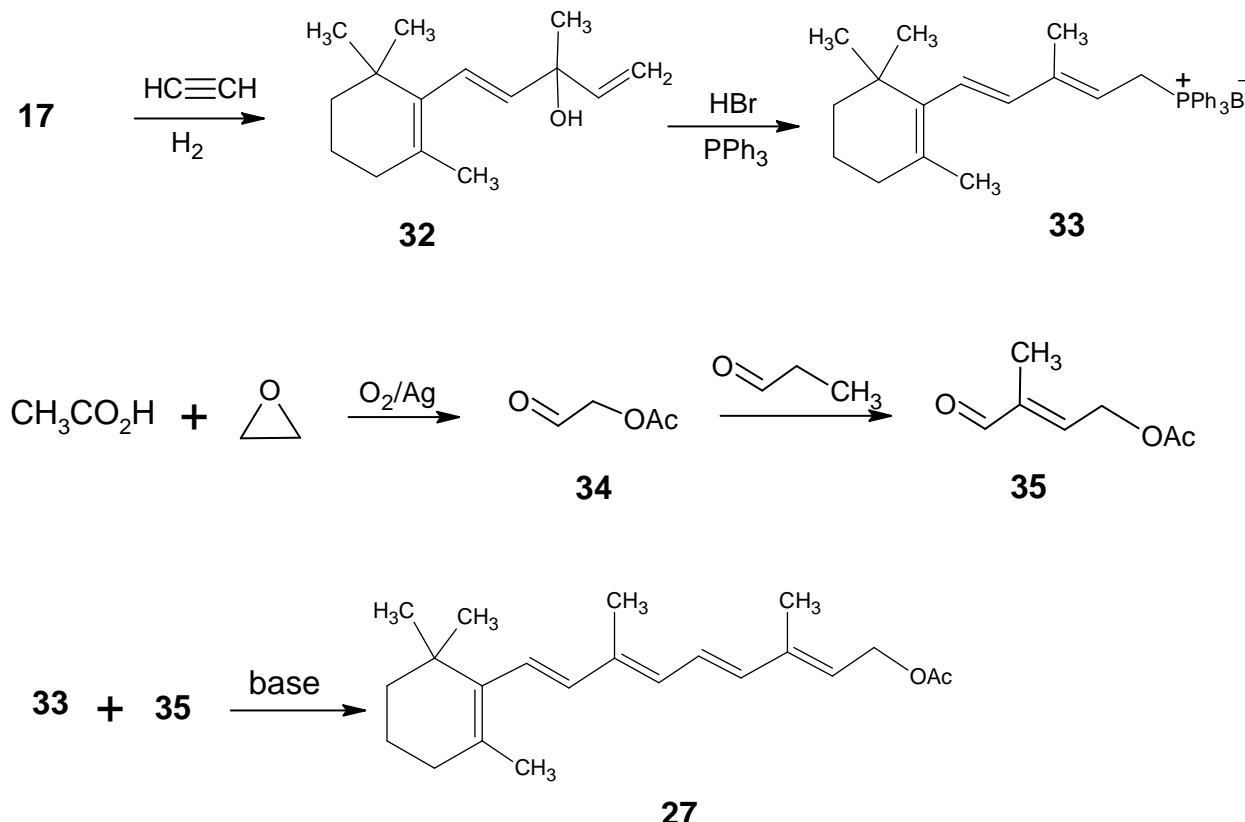

$70 \%$ all-E retinyl acetate $+30 \% 11 Z$-retinyl acetate

In this technical process also catalytic reactions are used to minimize the side products. A significant contribution to the cost is the preparation of triphenylphosphine at an industrial scale. The resulting triphenylphosphine oxide has a very strong $\mathrm{P}-\mathrm{O}$ bond which makes reconversion into triphenylphosphine expensive and difficult. Initially, the triphenylphosphine oxide was reconverted into triphenylphosphine and reused. Nowadays the residual triphenylphosphine oxide is pyrolysed.

\section{Part C. Site-Directed Highly Stable Isotope Enriched Retinals}

\section{Deuterium Labeled Retinals}

Highly enriched (99\%) starting materials available for deuterium incorporation are $\mathrm{D}_{2} \mathrm{O}$, $\mathrm{LiAlD}_{4}$, $\mathrm{NaBD}_{4}, \mathrm{CD}_{3} \mathrm{I}, \mathrm{CD}_{3} \mathrm{CN},\left(\mathrm{CD}_{3}\right)_{2} \mathrm{CO}$. Especially with deuterium incorporation the reactions used in the synthetic procedures should not lead to deuterium loss or scrambling. Also, after the primary deuterium incorporation the number of synthetic steps should be minimal with possible conversions to get the target molecule in a reasonable yield.

\subsection{Incorporation of deuterium at positions 18 and 19 of retinal 1: Preparation of $11 Z-\left[18-D_{3}\right]-$} retinal and $11 Z-\left[19-D_{3}\right]$-retinal via $\left[12-D_{3}\right]-\beta$-ionone 17 and $\left[13-D_{3}\right]-\beta$-ionone $17 b$, respectively

The reactions shown in the synthetic route in Scheme 7 are used for the preparation of [12- $\left.\mathrm{D}_{3}\right]-\beta$ ionone $\mathbf{1 7} \mathbf{a}$ and $\left[13-\mathrm{D}_{3}\right]$ - $\beta$-ionone $\mathbf{1 7} \mathbf{b}$ [85]. The starting material 2,2-dimethylcyclohexanone $\mathbf{3 6}$ is treated with methanolate base to afford the anion of $\mathbf{3 6}$ which upon reaction with $\mathrm{CD}_{3} \mathrm{I}$ a mixture of mono and bistrideuteromethylated products is obtained together with residual 36. After purification the 
product 37 is treated with the dianion of 1-butyn-3-ol (prepared by the reaction of 1-butyn-3-ol with 2 equivalents of EtMgBr) to obtain the product $\mathbf{3 8}$ with the full carbon skeleton of $\beta$-ionone.

Scheme 7. Conversion of 2,2-dimethylcyclohehexanone 36 into [12- $\left.\mathrm{D}_{3}\right]-\beta$-ionone $\mathbf{1 7 a}$. Base catalyzed conversion of $\beta$-ionone 17 into [13- $\left.\mathrm{D}_{3}\right]-\beta$-ionone $\mathbf{1 7 b}$. IUPAC numbering of $\beta$-ionone 17 is given in Scheme 2.

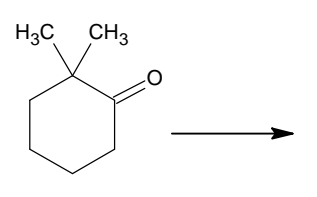

36

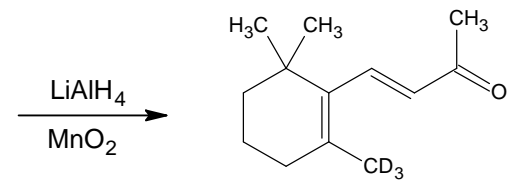

$17 a$

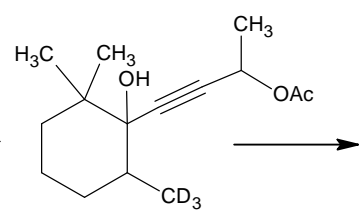

38

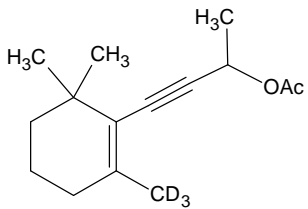

39

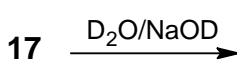

$17 b$

The secondary hydroxyl group is acetylated and the tertiary hydroxyl group is eliminated by the treatment with $\mathrm{POCl}_{3} /$ pyridine to give the enyne 39. Reduction of triple bond of the product 39 with $\mathrm{LiAlH}_{4}$ and $\mathrm{H}_{2} \mathrm{O}$ according to Scheme 8 afforded [12- $\left.\mathrm{D}_{3}\right]-\beta$-ionol which is converted into the corresponding [12- $\mathrm{D}_{3}$ ]- $\beta$-ionone 17a upon $\mathrm{MnO}_{2}$ oxidation. For the conversion of $\left[12-\mathrm{D}_{3}\right]-\beta$-ionone 17a into [18- $\mathrm{D}_{3}$ ]-retinyl acetate the reactions depicted in Scheme 6 are carried out. After saponification of $\left[18-\mathrm{D}_{3}\right]$-retinyl acetate (a mixture of $70 \%$ all- $E$ and $30 \% 11 Z$ ) the retinols are obtained which are converted into retinals via $\mathrm{MnO}_{2}$ oxidation. With preparative HPLC techniques the required 11Z-[18$\mathrm{D}_{3}$ ]-retinal is separated. The all- $E$ retinal in acetonitrile is treated with light (tungsten). After work-up an additional amount of $11 Z-\left[18-\mathrm{D}_{3}\right]$ retinal is isolated in pure form.

The protons of the methyl group attached to carbonyl group in $\beta$-ionone $\mathbf{1 7}$ are acidic, twice base catalyzed hydrogen-deuterium exchange in $\mathrm{D}_{2} \mathrm{O}$ /pyridine afforded more than $95 \%$ trideuterium incorporation at the methyl carbon to give [13- $\left.\mathrm{D}_{3}\right]-\beta$-ionone $\mathbf{1 7 b}$. Using $\mathbf{1 7 b}$ as a starting material for the reactions in Scheme $611 Z-\left[19-\mathrm{D}_{3}\right]$-retinal with deuterium incorporation of $>99 \%$ is obtained.

Scheme 8. Specific protonation or deuteration in the conversion of a propargylic alcohol into an allylic alcohol, $\left(m=1, \mathrm{LiAlH}_{4} ; \mathrm{m}=2, \mathrm{LiAlD}_{4} ; \mathrm{n}=1, \mathrm{H}_{2} \mathrm{O} ; \mathrm{n}=2, \mathrm{D}_{2} \mathrm{O}\right)$.
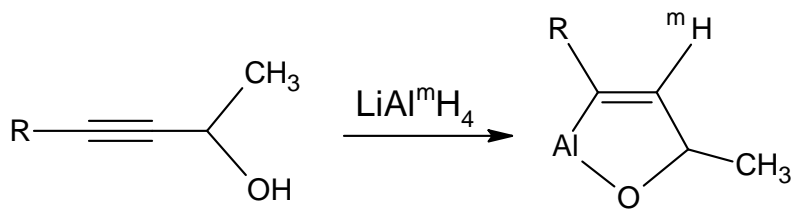

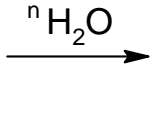

$\mathrm{m}, \mathrm{n}=1$ or 2<smiles>[R]C([2H])=C([2H])C(C)O</smiles> 
1.2. Incorporation of deuterium at positions 10, 11, 12, 14 and 20 of retinal 1: Preparation of all-E [10-D]-retinal, all-E [11-D]-retinal, all-E [12-D]-retinal, all-E [11,12-D2]-retinal, all-E [10,11-D $]$ retinal, all-E [14,20,20,20-D $]$-retinal

It has been discussed in Scheme 6 that $\beta$-ionone 17 upon treatment with the acetylide anion afforded acetylenic alcohol. This alcohol is treated with $\mathrm{LiAlD}_{4}$ and subsequent work-up gave [10-D]vinyl ionol which is converted into [10-D]-retinal following the synthetic route presented in Scheme 6 [86]. This product showed deuterium incorporation of about $82 \%$.

For the preparation of [11-D], [12-D] and [11,12-D $]$-retinals the propargylic alcohol 43 (triple bond between carbon 11 and carbon 12) with the full vitamin A skeleton has to be prepared via Scheme 9 [87]. $\beta$-Ionone 17 is treated with propargyl magnesium halide to give propargylic alcohol 40. Dehydration of $\mathbf{4 0}$ gave the trienyne $\mathbf{4 1}$ in two isomeric forms. The anion of $\mathbf{4 1}$ is coupled with 4,4-dimethoxylbut-2-one $\mathbf{4 2}$ to give the required propargylic alcohol $\mathbf{4 3}$.

The $\mathrm{LiAlD}_{4}$ treatment of product $\mathbf{4 3}$ as in Scheme 8 afforded deuterium incorporation at positions 11 and 12. Further work-up in acidic medium eliminated the alcohol function and deprotected the acetal function to give all- $E$ [11-D]-retinal, all- $E$ [12-D]-retinal and all- $E$ [11,12-D 2$]$-retinal with site-directed high deuterium incorporation. The final acid catalyzed removal of hydroxyl function and deprotection are very critical steps. However, these reactions should be performed quickly before isotopic loss and scrambling take place.

For the preparation of [10-D]-retinal, [11-D]-retinal, [10,11-D $]$-retinal, propargylic alcohol 45 (triple bond between carbon 10 and carbon 11) are prepared. First, 4,4-dimethoxylbut-2-one 42 is reacted with propargyl magnesium halide, then water is eliminated to give the enyne 44. This building block is converted into the anion and coupled with $\beta$-ionone $\mathbf{1 7}$ to give the propargylic alcohol $\mathbf{4 5}$ with the full retinal carbon skeleton. The deuteration/protonation and deprotection procedure as discussed above gave the required deuterated retinals. For the preparation of [14,20,20,20- $\left.\mathrm{D}_{4}\right]$-retinal, first 4,4-dimethoxybut-2-one 42 is pentadeuterated via a suspension of $\mathbf{4 2}$ in $\mathrm{D}_{2} \mathrm{O}$ in the presence of a catalytic amount of $\mathrm{K}_{2} \mathrm{CO}_{3}$. Following the reactions mentioned in Scheme 9 and final work-up the required deuterated retinal is obtained with ca. $80 \%$ tetradeuterium incorporation.

Scheme 9. The conversion of $\beta$-ionone 17 into propargylic alcohols 43 and $\mathbf{4 5}$ with full retinal carbon skeleton.

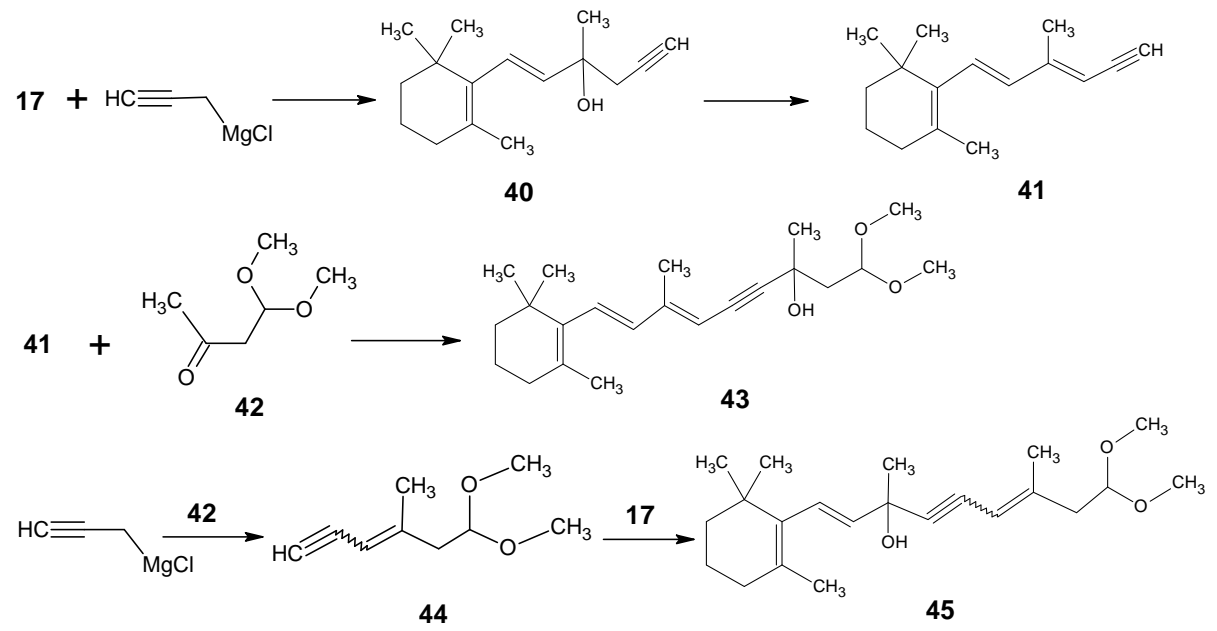


1.3. Incorporation of deuterium at positions 14,15, and 20 of retinal 1: Preparation of all-E [14-D]retinal, all-E [15-D]-retinal, all-E [14,15-D $]$-retinal and all-E [20,20,20-D $]$-retinal.

For the incorporation of deuterium at positions 14, 15 and 20 the reactions depicted in Scheme 10 are used. Peterson olefination of $\beta$-ionone 17 with silylcarbanion of [ $N$-(2'-t-butylsilyl)-ethylidene]-2methylpropane-2-amine gave $\beta$-ionylidene acetaldehyde 46 [88]. Base catalyzed aldol condensation with acetone 8 gave $\mathrm{C}_{18}$ ketone $\mathbf{4 7}$ which is converted into retinal $\mathbf{1}$ via a second Peterson Olefination reaction. Another approach is to treat $47\left(\mathrm{C}_{18}\right.$ ketone) with the anion of acetonitrile (prepared by treating acetonitrile with BuLi at low temperature) and subsequent elimination of a molecule of water afforded retinonitrile 48 which upon DIBAL-H reduction afforded retinal 1.

Use of $\mathrm{CD}_{3} \mathrm{CN}$ in the reaction in Scheme 10 afforded [14-D]-retinal. The conversion of [14-D]retinal into [14-D]-methyl retinoate is achieved via successive treatment with $\mathrm{MnO}_{2}, \mathrm{KCN}, \mathrm{CH}_{3} \mathrm{OH}$, $\mathrm{CH}_{3} \mathrm{CO}_{2} \mathrm{H}$. The methyl ester upon reduction with $\mathrm{LiAlD}_{4}$ yielded [14,15,15- $\left.\mathrm{D}_{3}\right]$-retinol. Subsequent $\mathrm{MnO}_{2}$ oxidation gave [14,15- $\left.\mathrm{D}_{2}\right]$-retinal. Similarly, LiAlD 4 reduction of methyl retinoate afforded [15,15- $\mathrm{D}_{2}$ ]-retinol. Oxidation of the later with $\mathrm{MnO}_{2}$ gave [15-D]-retinal. To obtain [20,20,20- $\left.\mathrm{D}_{3}\right]-$ retinal hexadeuterated acetone in the aldol condensation of $\mathbf{4 6}$ should be used. An alternative method of deuterium incorporation at carbon 18 (methyl ketone) in product 47 is by mixing the product in $\mathrm{D}_{2} \mathrm{O}$ in the presence of a catalytic amount of $\mathrm{NaOD}$ (similar to reactions shown in Scheme 7).

Scheme 10. Conversion of $\beta$-ionone 17 into retinal 1.

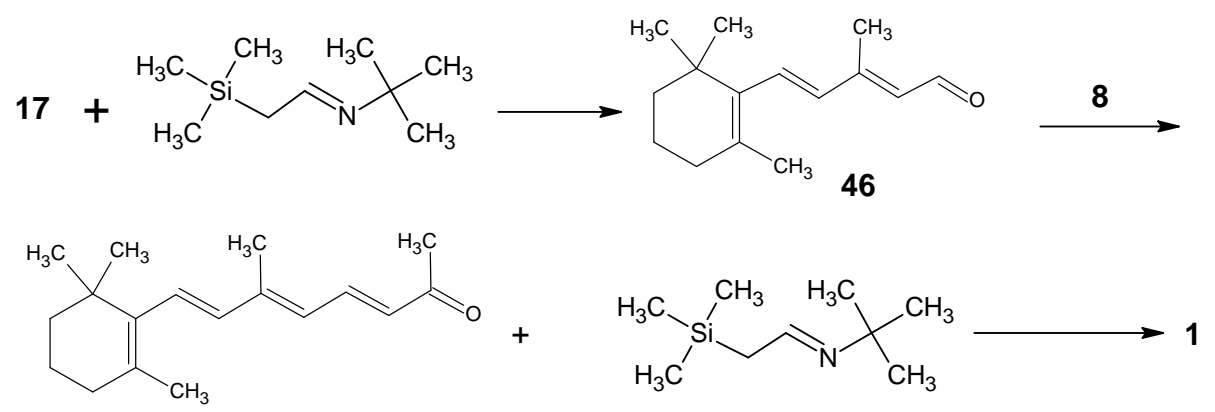

47

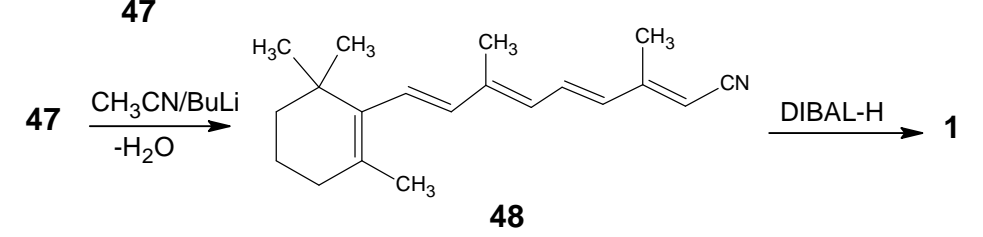

\section{2. ${ }^{13} \mathrm{C}$-Labeled Retinals}

${ }^{13} \mathrm{C}$-Enriched retinals are prepared via the use of ${ }^{13} \mathrm{CH}_{3} \mathrm{CN}, \mathrm{CH}_{3}{ }^{13} \mathrm{CN}$, and ${ }^{13} \mathrm{CH}_{3}{ }^{13} \mathrm{CN}$. Acetonitrile is commercially available in the three possible highly enriched ${ }^{13} \mathrm{C}$ isotopomers.

2.1. Incorporation of ${ }^{13} \mathrm{C}$ at positions 14 and 15 of retinal 1: Preparation of [14- $\left.{ }^{13} \mathrm{C}\right]$-retinal, [15$\left.{ }^{13} \mathrm{C}\right]$-retinal and $\left[14,15-{ }^{13} \mathrm{C}_{2}\right]$-retinal

Following the synthetic route mentioned in Scheme $10{ }^{13} \mathrm{C}$-labeled retinonitrile is obtained by the use of ${ }^{13} \mathrm{C}$-labeled acetonitrile. DIBAL-H reduction of the corresponding nitrile function in ${ }^{13} \mathrm{C}$-labeled 
retinonitriles gave $\left[14-{ }^{13} \mathrm{C}\right]$-retinal, $\left[15-{ }^{13} \mathrm{C}\right]$-retinal and $\left[14,15-{ }^{13} \mathrm{C}_{2}\right]$-retinal [88]. Also, the ${ }^{13} \mathrm{CD}_{3}$ enriched acetonitrile is commercially available. That means all ${ }^{2} \mathrm{H}$ and ${ }^{13} \mathrm{C}$ isotopomers at positions 14 and 15 of retinal 1 are accessible via the reactions discussed above.

In Scheme 11 it is shown that an Arbuzov reaction of triethylphosphite and chloroacetonitrile gave diethyl phosphonoacetonitrile 49 and subsequent treatment of the product with one equivalent of lithium diisopropylamide (LDA) in THF afforded the anion of 49 in situ. An alternative way to obtain the anion of 49 in ${ }^{13} \mathrm{C}$ isotopomeric form is by reacting ${ }^{13} \mathrm{C}$-enriched acetonitrile with two equivalents of LDA and then adding one equivalent of diethyl chlorophosphate. 4-Chloro-3-methylbut-2-enenitrile is obtained by the HWE reaction of 49 with 1-chloroacetone and further Arbuzov reaction with triethylphosphite gave a mixture of (Z/E)-4-(diethylphosphono)-3-methylbut-2-enenitrile $\mathbf{5 0 .}$

Scheme 11. Preparation of Horner-Wadsworth-Emmons (HWE) reagents: diethyl phosphonoacetonitrile 49 and 4-(diethylphosphono)-3-methylbut-2-enenitrile 50.

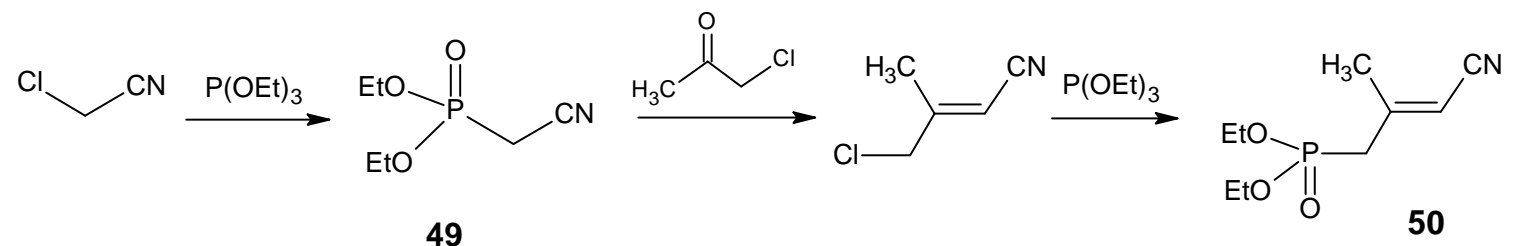

Retinals with ${ }^{13} \mathrm{C}$ enrichment at positions 8, 9, 10, 11, 12, 13, 14, 15, 19 and 20 are accessible via the synthetic route depicted in Scheme 12 [89,90]. $\beta$-Cyclocitral 51 is treated with the anion of 49 to give the conjugated nitrile 52 which upon DIBAL-H reduction afforded the conjugated aldehyde 53. The aldehyde 53 is treated with $\mathrm{CH}_{3} \mathrm{MgI}$ to give $\beta$-ionol which upon $\mathrm{MnO}_{2}$ oxidation gave $\beta$-ionone 17. The Grignard reagent methylmagnesium iodide can also be obtained in $99 \%{ }^{13} \mathrm{C}$-enriched form by treating commercially available ${ }^{13} \mathrm{CH}_{3} \mathrm{I}$ with magnesium. Any ${ }^{13} \mathrm{C}$ isotopomer of $\mathbf{1 7}$ is accessible via Scheme 12 by using the right sequence of isotope enriched reagents and the reagents in natural isotope abundance form.

Scheme 12. Preparation of retinals with ${ }^{13} \mathrm{C}$ enrichment at positions $8,9,10,11,12,13,14,15$, 19 and 20.<smiles>CC1=C(C=O)C(C)(C)CCC1</smiles>

51<smiles>CC(=O)/C=C/C1=C(C)CCCC1(C)C</smiles>

17<smiles>CC1=C(/C=C/C#N)C(C)(C)CCC1</smiles>

52

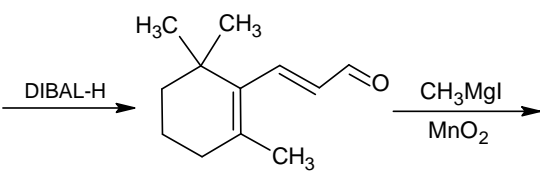

53

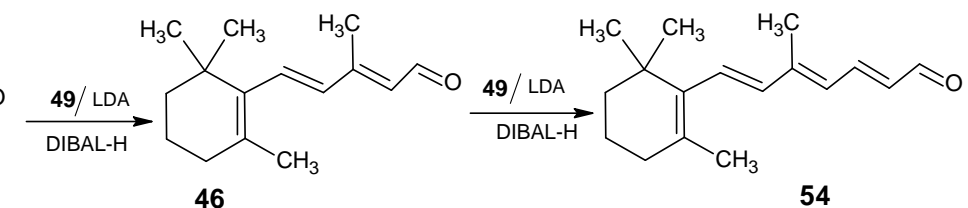

46<smiles>CC(=O)/C=C/C=C(C)/C=C/C1=C(C)CC[C@@H]([N+](=O)[O-])C1(C)C</smiles><smiles>CC1=C(/C=C/C(C)=C/C=C/C(C)=C/C=O)C(C)(C)CCC1</smiles> 
2.2. Incorporation of ${ }^{13} \mathrm{C}$ in the six membered ring of retinal 1: Preparation of $\left[1{ }^{13} \mathrm{C}\right]-,\left[2-^{13} \mathrm{C}\right]-$, $\left[1,3-{ }^{13} C_{2}\right]-$ and $\left[1,2,3-{ }^{13} C_{3}\right]-,\left[3-{ }^{13} C\right]-,\left[4-{ }^{13} C\right]-,\left[5-{ }^{13} C\right]-,\left[4,5-{ }^{13} C_{2}\right]-,\left[6-{ }^{13} C\right]-,\left[7-{ }^{13} C\right]-$, and $\left[18-{ }^{13} \mathrm{C}\right]$ - retinal

In Scheme 13 the synthetic route is depicted to show that commercial 5-chloropent-2-one $\mathbf{5 5}$ is used as a starting material to obtain final $\left[1-{ }^{13} \mathrm{C}\right]$-retinal and $\left[16,17-{ }^{13} \mathrm{C}_{2}\right]$-retinal. The product 55 is converted into the acetal with ethylene glycol and subsequent treatment with $\mathrm{KI}$ in acetone gave the iodoacetal 56. Treatment with triphenylphosphine yielded the phosphonium iodide 57 which upon treatment with BuLi gave the ylide that coupled with acetone 8 to give the acetal of 12. Deprotection of acetal afforded 6-methylhep-5-en-2-one 12. After conversion of product 12 to pseudoionone 16 followed by the acid treatment afforded $\beta$-ionone 17 [91].

Acetone is available in $\left[1-{ }^{13} \mathrm{C}\right]-,\left[2-{ }^{13} \mathrm{C}\right]-,\left[1,3-{ }^{13} \mathrm{C}_{2}\right]-$ and $\left[1,2,3-{ }^{13} \mathrm{C}_{3}\right]$-isotopomeric form. In the case of the $\left[1-{ }^{13} \mathrm{C}\right]$-acetone a $50 / 50$ mixture of the $\left[16-{ }^{13} \mathrm{C}\right]$ and $\left[17-{ }^{13} \mathrm{C}\right]$ retinal is obtained. With $\left[2-{ }^{13} \mathrm{C}\right]-,\left[1,3-{ }^{13} \mathrm{C}_{2}\right]-$ and $\left[1,2,3-{ }^{13} \mathrm{C}_{3}\right]$-acetone well defined isotopically enriched retinals are obtained.

Scheme 13. Conversion of 5-chloropenta-2-one 55 into $\beta$-ionone 17.
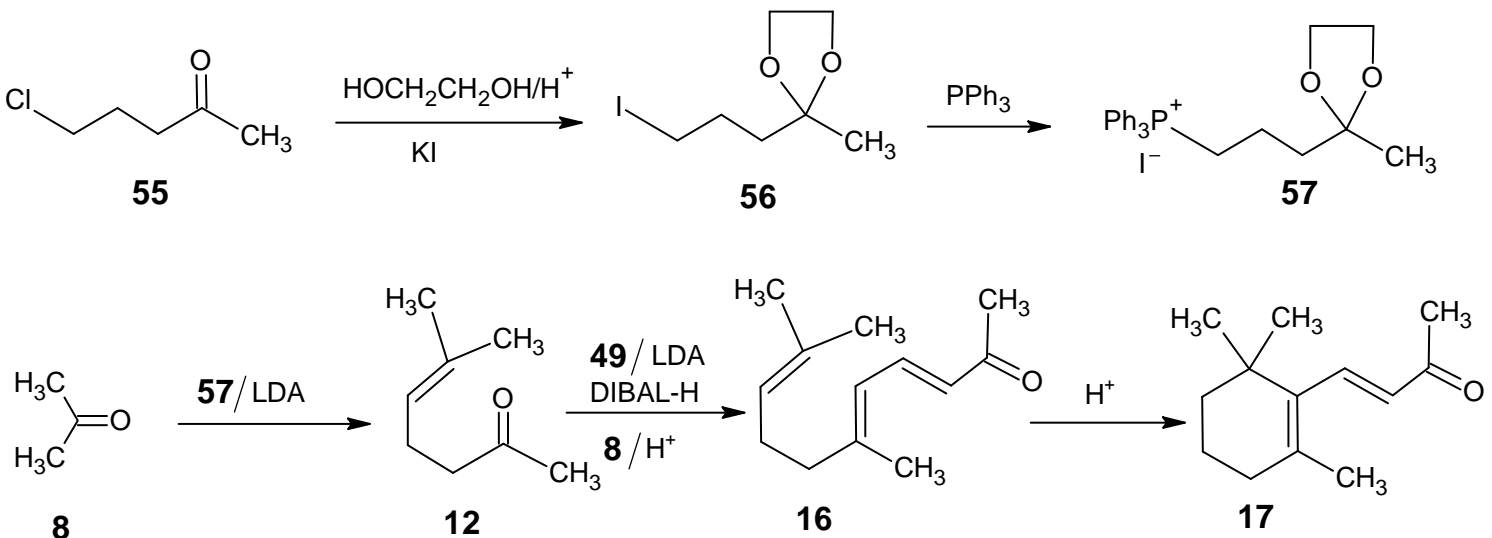

For the chain extension of $\beta$-ionone $\mathbf{1 7}$ we have used the building block $\mathbf{5 0}$ which is prepared via the synthetic route depicted in Scheme 11. In order to effect a more efficient conversion of $\beta$-ionone $\mathbf{1 7}$ into isotopically labeled retinals the ${ }^{13} \mathrm{C}$-enriched phosphonates $\mathbf{4 9}$ and $\mathbf{5 0}$ described in Scheme 11 are used. (E/Z)- $\beta$-Ionylidene acetonitrile is obtained by the HWE reaction of the anion of 49 with $\beta$-ionone 17 which upon DIBAL-H reduction gave the $(E / Z)-\beta$-ionylidene acetaldehyde 46 (Scheme 12). Product 46 is treated with the anion of $\mathbf{5 0}$ to form a mixture of geometric isomers of retinonitrile $\mathbf{4 8}$ which is further reduced by DIBAL-H to obtain a mixture of geometric isomers of retinal $\mathbf{1}$ (Scheme 10). The use of building blocks 49 and $\mathbf{5 0}$ together with subsequent nitrile to aldehyde reduction made these schemes much more efficient.

For the incorporation of ${ }^{13} \mathrm{C}$ at positions 4 and 5 of retinal 1 the reactions in Scheme 14 are worked out. Commercially available 1-bromo-3-methylbut-2-ene $\mathbf{5 8}$ is treated with an equivalent of the anion of acetonitrile (prepared by 1 eq. BuLi in THF) to give 5-methylhex-4-enenitrile 59. Treatment of 59 with methyllithium afforded 6-methylhept-5-ene-2-one $\mathbf{1 2}$ which is converted into $\beta$-ionone 17 via synthetic routes depicted in Scheme 13. By using ${ }^{13} \mathrm{C}$-enriched acetonitrile $\left[4-{ }^{13} \mathrm{C}\right]-,\left[5-{ }^{13} \mathrm{C}\right]-$, and $\left[4,5-{ }^{13} \mathrm{C}_{2}\right]$-retinals are obtained. 
Scheme 14. Preparation of 6-methylhept-5-ene-2-one 12.

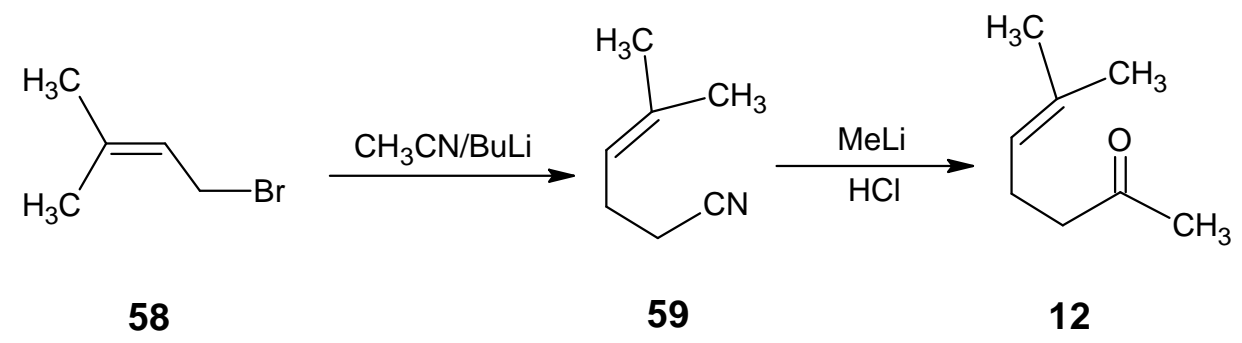

The reactions in Scheme 15 are used for a less expensive alternative for the preparation of $\left[18-{ }^{13} \mathrm{C}\right]-$ retinal. Commercially available 4-oxopentan-1-ol $\mathbf{6 0}$ is first acetylated, then treated with the anion of triphenylmethyl phosphonium bromide and subsequently saponified. The resulting alcohol is converted into the tosylate 61. Treatment with $\mathrm{KCN}$ gave the isomer of nitrile 59 (iso-59) and methylmagnesium iodide converted this product into iso-12. This is converted into isocitral (iso-31) via the reaction with diethyl phosphonoacetonitrile 49 and subsequent DIBAL-H reduction followed by condensation with acetone $\mathbf{8}$ afforded iso-pseudoionone. Presence of an acid converted it into $\beta$ ionone 17. Using $\mathrm{K}^{13} \mathrm{CN},{ }^{13} \mathrm{CH}_{3} \mathrm{MgI}$ and ${ }^{13} \mathrm{C}$-labeled acetonitrile gave at the end $\left[5-{ }^{13} \mathrm{C}\right]-$, [6- $\left.{ }^{13} \mathrm{C}\right]-$, [7$\left.{ }^{13} \mathrm{C}\right]$-, and $\left[18-{ }^{13} \mathrm{C}\right]$-retinals.

Scheme 15. Conversion of commercially available 4-oxopentan-1-ol 60 into iso-12.<smiles>CC(=O)CCCO</smiles>

60<smiles>C=C(C)CCC[Se-]</smiles>

61<smiles>C=C(C)CCCC#N</smiles>

iso-59<smiles>C=C(C)CCC(C)=O</smiles>

iso-12

For ${ }^{13} \mathrm{C}$-incorporation at positions 2 and 3 of retinal the reactions of the synthetic route in Scheme 16 are followed. Commercially available ethyl 3-methylbut-2-enoate $\mathbf{6 2}$ via NBS bromination and subsequent DIBAL-H reduction is converted into the unsaturated bromoalcohol 63 [92]. Protection of the alcohol function with tert-butylmethylsilyl chloride and treatment with $\mathrm{NaI}$ in acetone yielded the iodide 64 which is treated with the anion of acetonitrile to give the nitrile 65. DIBAL-H reduction of 65 and subsequent treatment with isopropylidene(triphenylphosphorane) and deprotection gave citrol 66. Treatment of 66 with $\mathrm{MnO}_{2}$ afforded citral 31. Citral 31 is converted into $\beta$-ionone 17 (Scheme 5) and finally into retinal 1 via the reactions mentioned in Scheme 12 . Use of ${ }^{13} \mathrm{C}$-labeled acetonitrile in the reaction with product 64 afforded $\left[2-{ }^{13} \mathrm{C}\right]$ - and $\left[3-{ }^{13} \mathrm{C}\right]$-retinals. 
Scheme 16. Conversion of ethyl 3-methylbut-2-enoate 62 into citrol 66.<smiles>CCOC(=O)C=C(C)C</smiles>

62

63

64

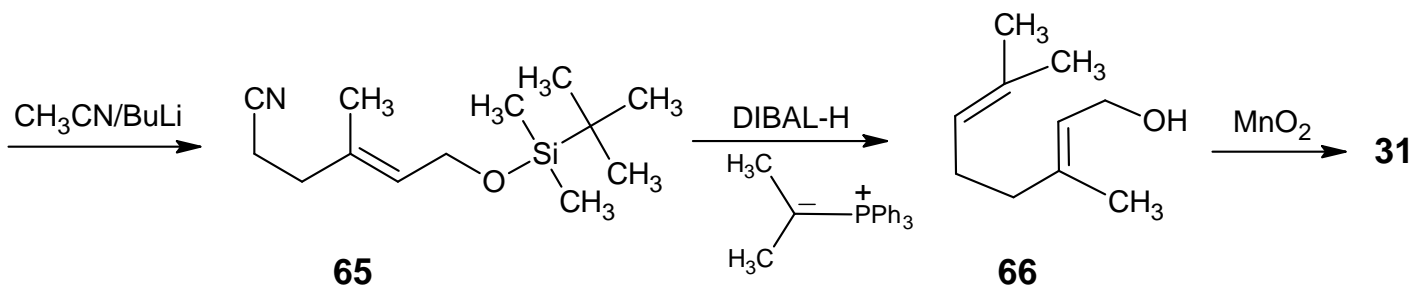

The Schemes 10-16 have given possibility of a large number of site-directed ${ }^{13} \mathrm{C}$-enriched retinals. In principle all ${ }^{13} \mathrm{C}$ isotopomers of retinals are now accessible. However, due to chirality of carbon 1 ${ }^{13} \mathrm{C}$-enrichment only at either position 16 or position 17 leads to inseparable mixtures of enantiomers in the final retinal $\mathbf{1}$.

\subsection{Incorporation of ${ }^{13} \mathrm{C}$ at all positions of retinal 1: Preparation of $\left[\mathrm{U}_{-}^{13} \mathrm{C}\right]$-retinal}

In order to obtain highly ${ }^{13} \mathrm{C}$-enriched up to the $\left[\mathrm{U}_{-}{ }^{13} \mathrm{C}\right]$-retinal a more convergent reaction Scheme with highly ${ }^{13} \mathrm{C}$-enriched building blocks is developed [52]. In Scheme 17 the reactions are depicted that lead to any site-directed ${ }^{13} \mathrm{C}$-enriched $\beta$-cyclocitral 51. Acetic acid is converted via Hell-VolhardtZelinsky bromination and subsequent esterification into ethyl bromoacetate 67. An Arbuzov reaction of 67 with the triethylphosphite gave ethyl diethylphosphonoacetate $\mathbf{6 8}$. The HWE coupling of the product 68 with acetone 8 gave ethyl 3-methylbut-2-enoate 62. Reduction of 62 with $\mathrm{LiAlH}_{4}$ and subsequent bromination of the allylic alcohol afforded 1-bromo-3-methylbut-2-ene 58. Ethyl 3-oxobutanoate $\mathbf{7 0}$ is commercially available in all ${ }^{13} \mathrm{C}_{4}$ form.

All other isotopomers are prepared via the Blaise reaction of acetonitrile with the ethyl zinciodoacetate 69. Ethyl iodoacetate is obtained by the reaction of product 67 with $\mathrm{KI}$ in acetone which is further treated with zinc to obtain product 69 in situ. Base induced coupling of 58 and ester 70 afforded the product which after saponification and acid catalyzed $\mathrm{CO}_{2}$ removal gave the product 12 . The HWE coupling of 12 with diethyl phosphonoacetonitrile 49 gave 3,7-dimethylocta-2,6-dienenitrile 71. The open chain nitrile $\mathbf{7 1}$ is then cyclized to $\alpha$-cyclocitronitrile $\mathbf{7 2}$ with the concentrated sulfuric acid in nitromethane. The ring closure mainly gave the nitrile with the double bond in $\alpha$-position. In the work-up procedure, it is proved to be important to keep the condition acidic to avoid a double bond shift to the $\beta$-position. $\alpha$-Cyclocitronitrile 72 which upon DIBAL-H reduction and subsequent base treatment is converted into $\beta$-cyclocitral 51. All starting materials used in this scheme namely acetic acid, acetonitrile and acetone are commercially available in any ${ }^{13} \mathrm{C}$-enriched form. $\beta$-Cyclocitral $\mathbf{5 1}$ is very efficiently converted into $\beta$-ionylidene acetaldehyde 46 via the HWE coupling with (4-diethylphosphono)-3-methylbut-2-enenitrile $\mathbf{5 0}$ (Scheme 11) and subsequent DIBAL-H reduction of nitrile function (Scheme 12). Further coupling of aldehyde 46 with $\mathrm{C}_{5}$-phosphonate $\mathbf{5 0}$ and subsequent DIBAL-H reduction of nitrile function of retinonitrile $\mathbf{4 8}$ (Scheme 10) afforded retinal 1. 
Scheme 17. The synthesis of $\beta$-cyclocitral 51 in any site-directed ${ }^{13} \mathrm{C}$-enriched form.

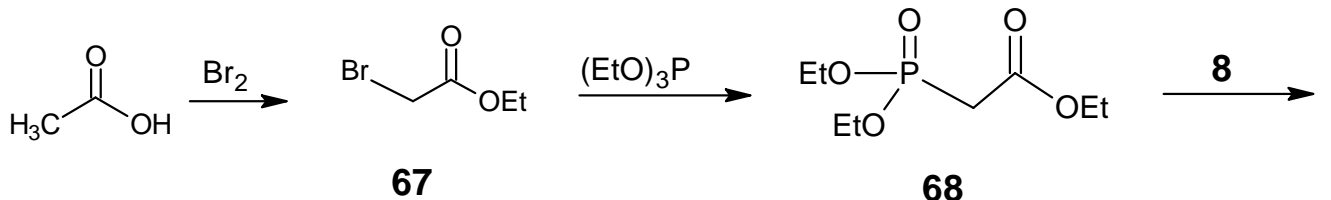<smiles>CCOC(=O)C=C(C)C</smiles>

62<smiles>CC(C)=CCBr</smiles>

58

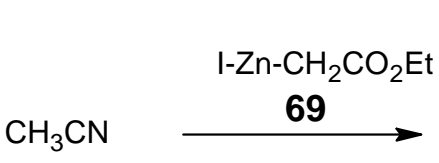<smiles>CCOC(=O)CC(C)=O</smiles>

70
58<smiles>CC(=O)CCC=C(C)C</smiles>

12

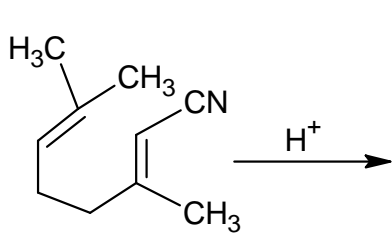

71<smiles>CC1=CCCC(C)(C)C1C#N</smiles>

72<smiles>CC1=C(C=O)C(C)(C)CCC1</smiles>

51

The isotopomers of (4-diethylphosphono)-3-methylbut-2-enenitrile $\mathbf{5 0}$ are obtained via the reactions mentioned in Scheme 12. The necessary starting reagent is isotopically labeled 1-chloroacetone which is obtained from isotopically labeled ethyl 3-oxobutanoate 70. The anion of ethyl 3-oxobutanoate $\mathbf{7 0}$ is treated with $\mathrm{SO}_{2} \mathrm{Cl}_{2}$ to give the ethyl 2-chloro-3-oxobutanoate. Acid catalyzed $\mathrm{CO}_{2}$ expulsion gave 1-chloroacetone in any isotopically enriched form. Diethyl phosphonoacetonitrile 49 can also be obtained in any isotopomeric form by treating the anion of ${ }^{13} \mathrm{C}$-enriched acetonitrile with diethyl chlorophosphate.

The $\mathrm{LiAlH}_{4}$ reduction of ethyl 3-methylbut-2-enoate 62 to the required allylic alcohol (before bromination step) is obtained in low yield. An alternative high yield method is the reaction of acetone 8 with diethyl phosphonoacetonitrile 49 to give 3-methylbut-2-enenitrile. Subsequent DIBAL-H reduction of nitrile function afforded an aldehyde and reduction of the aldehyde with $\mathrm{NaBH}_{4}$ gave 3-methylbut-2-en-1-ol which upon bromination afforded 1-bromo-3-methylbut-2-ene 58.

It has been observed that the anion of $\mathrm{C}_{5}$-phosphonate $\mathbf{5 0}$ (prepared in such a way that no base is present in the reaction mixture) reacted with $\beta$-cyclocitral $\mathbf{5 1}$ at room temperature to give only all- $E$ $\beta$-ionylidene acetaldehyde 46. The extension of product 46 up to retinal 1 under the same conditions gave only the pure $E$-isomer intermediates (Scheme 12) [93]. However, the stereochemistry depends on the substitution pattern of the phosphonate and the aldehyde and the conditions of the reaction.

The possibility of an $E / Z$ isomeric mixture in the reaction is due to the delocalized allylic anion structure of 50. In case of the anion of $\mathbf{5 0}$ above $-20{ }^{\circ} \mathrm{C}$ the isomerization is rapid leading within experimental error to only all- $E$ structure. The corresponding allylic anion in which the nitrile function is substituted by an ester function also showed rapid isomerization above $-20{ }^{\circ} \mathrm{C}$ but the thermodynamic equilibrium is composed of about $E / Z$ (1:1) isomeric anion mixtures [94]. 
$E$-Selectivity is exclusive due to thermodynamic preference of linear nitrile function in phosphonate derivative 50 compared to the triangular ester function of the corresponding phosphonate derivative.

It has been reported that a HWE reaction of the anion of ethyl diethylphosphonoacetate with aldehyde gives mainly E-product, where as the ethyl diphenylphosphonoacetate and the bis(trifluoroethyl)phosphonate ester give only $Z$ product [95,96]. It has been discussed that the formation of the more stable trans-olefin is reached via the threo-adduct whereas the better leaving diphenylphosphonate group reacts to give the cis-olefin via the erythro-adduct [97].

The HWE coupling of $\beta$-ionylidene acetaldehyde $\mathbf{4 6}$ with either the anion of 4-[bis(trifluoro)ethylphosphono]-3-methylbut-2-enenitrile or 4-(diphenylphosphono)-3-methylbut-2enenitrile gave in good yield $11 Z$-retinal mixed with the all- $E$ form $[93,98,99]$. The fact is that the presence of more electron withdrawing phosphonate in the allylic nitrile didn't give complete $Z$ formation as in the case of ethyl diethylphosphonoacetate. This can be explained by the greater stability of the allylic anion which leads to reversibility of the erythro-adduct to the starting reagents. Under these conditions also threo-adduct can form which gives trans isomer by the elimination of diphenyl phosphate salt. In the mean time via this method 3,4-didehydro-11Z-retinal and 7,8-dihydro$11 Z$-retinal have been prepared [100,101].

In order to test if a better leaving group would lead to the formation of 11Z-retinal only, the Arbuzov reaction of bis(4-nitrophenyl)methylphosphite with 4-chloro-3-methylbut-2-enenitrile was attempted, however even at very high temeperature no bis(4-nitrophenyl)methylphosphonate is formed. In order to test the possibilities for pure 11Z-retinal formation in a HWE reaction the required phosphonate with better leaving groups have to be prepared in another way than by Arbuzov reaction.

\section{Isotope Enriched Chemically Modified Retinals}

\subsection{Preparation of (11Z)-3,4-didehydroretinal, (3R)-(11Z)-3-hydroxyretinal and (4R)-(11Z)-4- hydroxyretinal}

Besides 11-Z retinal in some animals (11Z)-3,4-didehydroretinal, (3R)-(11Z)-3-hydroxyretinal and $(4 R)-(11 Z)-4$-hydroxyretinal are the chromophores of the visual pigment. The reactions depicted in the synthetic route in Scheme 18 are used for the preparation of above mentioned retinals [13]. $\alpha$-Cyclocitronitrile 72 (Schemes 17 and 18) is used as the starting material in which the double bond can easily be converted into an epoxide ring and subsequent treatment with a base gives $(R / S)-4$ hydroxy unsaturated nitrile 73. In the presence of acid a water molecule is eliminated to give the nitrile 74.

Treatment of $\mathbf{7 4}$ with m-chloroperbenzoic acid afforded the product $\mathbf{7 5}$ via the epoxidation of $\gamma, \delta$-double bond. DIBAL-H reduction of products 73, 74 and 75 afforded aldehydes (4RS)-4-hydroxy$\beta$-cyclocitral 76, safranal 77 and (3RS)-3-hydroxy- $\beta$-cyclocitral 78, respectively. The required (4R)(11Z)-4-hydroxyretinal, (11Z)-3,4-didehydroretinal and (3R)-(11Z)-3-hydroxyretinal, respectively are obtained by the HWE coupling of the aldehydes 76, 77 and 78 in Scheme 18 with the anion of the phosphonate $\mathbf{5 0}$ and subsequent DIBAL-H reduction of the corresponding nitrile function [13]. 
Scheme 18. The conversion of $\alpha$-cyclocitronitrile 72 into (4RS)-4-hydroxy- $\beta$-cyclocitral 76, safranal 77 and (3RS)-3-hydroxy- $\beta$-cyclocitral 78.<smiles>CC1=CCCC(C)(C)C1C#N</smiles>

72<smiles>C[14CH2]C1C=CC(C)=C(C#N)C1(C)C</smiles>

74<smiles>CC1=C(C=O)C(C)(C)CC=C1</smiles><smiles>CC1=C(C#N)C(C)(C)CC2OC12</smiles>

75<smiles>CC1=C(C=O)C(C)(C)CC(O)C1</smiles>

A serious drawback in the synthetic routes shown in Schemes 17 and 18 used for the preparation of retinals and chemically modified retinals with the modification in the six membered ring are linear, as a result lower yield of the required $\beta$-cyclocitral 51 and even lower yields of (4RS)-4-hydroxy- $\beta$ cyclocitral 76, safranal 77 and (3RS)-3-hydroxy- $\beta$-cyclocitral 78 are obtained.

A more convergent method to obtain the required $\beta$-cyclocitral derivatives in high yield is indicated in Scheme 19. The Knoevenagel reaction of 1-cyanoacetone $\mathbf{8 0}$ with acetone $\mathbf{8}$ and 1,1-dimethoxyacetone $\mathbf{7 9 b}$ has been reported [102]. Products $E / Z$ 4-methyl-3-cyanopent-3-ene-2-one 81a and E/Z 5,5-dimethoxy-4-methyl-3-cyanopent-3-ene-2-one 81b are obtained in high yield in a one-step procedure. The nucleophilic attack on these highly poor alkenes is expected to take place on carbon 4. In this case anion of acetone 8 is prepared from LDA at $-90{ }^{\circ} \mathrm{C}$ in THF. This is expected to lead to the anion 82. Subsequent reaction with diethyl chlorophosphate should result in the cyano enol phosphate 83 which is expected to undergo a ring closure to give 5-oxo- $\beta$-cyclocitronitrile $84 a$ or dimethoxy derivative of 5-oxo- $\beta$-cyclocitronitrile $\mathbf{8 4 b}$.

The reaction of 81c (the ester analogue of 81a) with the anion of allyltriphenylphosphonium bromide to obtain the citral derivative $\mathbf{8 4 c}$ in Scheme 19 has been reported [103]. This means that the reactions in Scheme 19 will lead to a very convenient method to obtain retinals with the ${ }^{13} \mathrm{C}$ enrichment in the six-membered ring or the chemically modified retinals with the modification in the six membered ring. The 16,17-dimethoxyretinals also open the possibility to obtain retinals that differ in isotope composition on carbons 16 and 17 in pure enantiomeric form. Previously, the Knoevenagel reaction has been used in the field of vitamin $A$ for the conversion of $\beta$-ionone 17 into $\beta$-ionylidene acetonitrile 85 [104]. 
Scheme 19. Preparation of $\beta$-cyclocitral derivatives via Knoevenagel condensation.<smiles>[R]C(C)=[O+]C(C)=O</smiles>

$$
\begin{array}{ll}
79 \mathrm{~b} \mathrm{R}=\mathrm{CH}\left(\mathrm{OCH}_{3}\right)_{2} & 81 \mathrm{a} \mathrm{R}=\mathrm{CH}_{3} \\
& 81 \mathrm{~b} \mathrm{R}=\mathrm{CH}\left(\mathrm{OCH}_{3}\right)_{2}
\end{array}
$$<smiles>[R]C(C)(CC(C)=O)C(C)=C(C)OP(=O)(OCC)OCC</smiles>

$84 \mathrm{a} \mathrm{R}=\mathrm{CH}_{3}$

$83 \mathrm{a} \mathrm{R}=\mathrm{CH}_{3}$ $83 \mathrm{~b} \mathrm{R}=\mathrm{CH}\left(\mathrm{OCH}_{3}\right)_{2}$<smiles>CCOC(=O)C(C(C)=O)=C(C)C</smiles>

$81 c$<smiles>C=CC[Pb]Br</smiles>

82

\subsection{Preparation of 10-methylretinal, 10-methylthioretinal, 10-iodoretinal and 19-fluororetinal via $\beta$ -} ionylidene acetonitrile $\mathbf{8 5}$

In Scheme 20 a synthetic route is depicted to obtain the chemically modified retinoids by using the reactivity of conjugated nitriles. $\beta$-Ionylidene acetonitrile $\mathbf{8 5}$ is treated with LDA in THF resulting in the allylic anion $\mathbf{8 6}$ by deprotonation of methyl group at postion 15 . Treatment of 86 with the electrophilic reagent $\mathrm{CH}_{3} \mathrm{I}$ gave 87a with the methyl group at position 10 . In the presence of an acid allylic shift occurred to give 10-methyl- $\beta$-ionylidene acetonitrile 88a [105].

Similarly, the allylic anion $\mathbf{8 6}$ with methyl thiocyanate, iodine and trimethylsilyl chloride gave 10 -methylthio- $\beta$-ionylidene acetonitrile $\mathbf{8 8 b}, 10$-iodo- $\beta$-ionylidene acetonitrile $\mathbf{8 8 c}$ and trimethylsilyl derivative $\mathbf{8 7 d}$, respectively. The later is treated with selectfluor ${ }^{(\mathrm{R})}$, followed by DIBAL-H reduction to obtain 15-fluoro- $\beta$-ionylidene acetaldehyde 89 [106]. The nucleophilic attack on the allylic trimethylsilanes is a general reaction, which means that a large number of 15 -substituted- $\beta$-ionylidene acetonitriles will be accessible via this method. DIBAL-H reduction of these commercially modified $\beta$-ionylidene acetonitriles will give the corresponding $\beta$-ionylidene acetaldehydes, which can easily be converted into the corresponding retinonitriles. 
Scheme 20. The preparation of chemically modified retinoids by using the reactivity of conjugated nitriles.

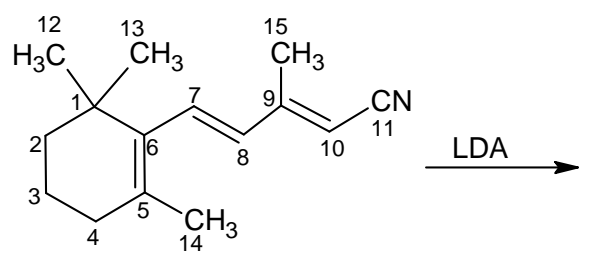

85<smiles>CC1=C(/C=C/C(C)=C/C#N)C(C)(C)CCC1</smiles>

86

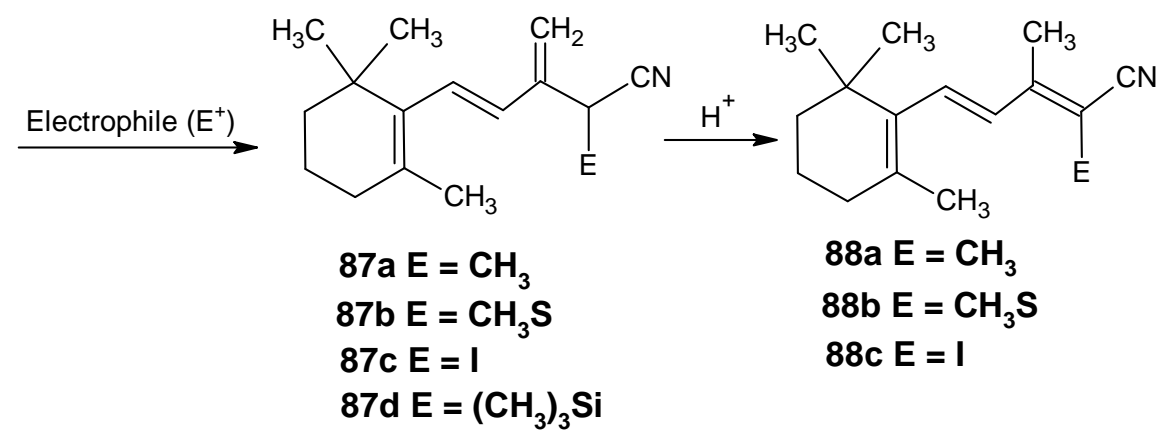<smiles>C=C(/C=C/C1=C(C)CCCC1(C)C)C([Si])[Si]C</smiles>

87d<smiles>CC1=C(/C=C/C(=C/C=O)CF)C(C)(C)CCC1</smiles>

89

Similarly, using building blocks 88a, 88b and 88c 10-methyl-, 10-methylthio-, and 10iodoretinonitriles are prepared, respectively [105]. It is clear that using the acidity of methyl groups in conjugated nitriles retinals with chemical modification or combinations of modifications at positions 10, 14, 19 and 20 are accessible. The required conjugated nitriles are accessible in any isotopically enriched form which means that chemically modified retinals are accessible via this method. Retinals modified with alkyl groups are available in any isotopically enriched form via above described method because the simple alkyl groups are available in any isotopically enriched form.

\subsection{Preparation of 11-methylretinal and 12-methylretinal via $\beta$-ionyl triphenylphosphonium bromide 90}

The preparation of 11-methylretinal is carried out via the reactions depicted in Scheme 21 . $\beta$-Ionyl triphenylphosphonium bromide $\mathbf{9 0}$ is refluxed in 1,2-epoxybutane in the presence of 3,5-dimethyl-6oxohexa-2,4-dienenitrile 91 [107]. The later is prepared via the HWE reaction of 1,1dimethoxyacetone 79b and the anion of the phosphonate 50 (Scheme 11) followed by the acetal deprotection to obtain the aldehyde 91. After DIBAL-H reduction (all-E)-11-methylretinal and (9Z)-11-methylretinal are obtained. The HPLC separation also gave a new product 93 in which the anion of 90 is reacted in a 1,4-addition to the conjugated aldehyde 91. After proton shift an internal Wittig reaction took place leading to the corresponding nitrile $\mathbf{9 3}$.

The 1,4-conjugated Wittig reactions that lead to 93 are known [108-112]. The ratio (all-E)-92:(9Z)$\mathbf{9 2 : 9 3}=1: 1: 2$ of the obtained products showed that (all-E)-92 and (9Z)-92 are formed in a 1:1 ratio that 
is in agreement with leaving group facility in triphenylphosphine oxide. This has been discussed in the industrial syntheses. When triphenylphosphonium bromide 94 is treated with the conjugated aldehyde 95 in refluxing 1,2-epoxybutane only (all-E)-92 and (11Z)-92 are formed just as in the BASF technical synthesis. Product 94 is prepared by methylation via Grignard reagent on $\beta$-ionylidene acetaldehyde 46 and subsequent triphenylphosphonium salt formation. Building block 95 has been prepared via coupling of 1,1-dimethoxyacetone $79 \mathrm{~b}$ and the anion of diethyl phosphonoacetonitrile 49. This improved synthesis of 11Z- and all-E 11-methylretinal 92 is depicted in lower line of Scheme 21. In this reaction no side product $\mathbf{9 3}$ is formed. It is clear that the 9-methyl group in the reagent 94 prevents the formation of products via 1,4-Wittig reaction. In the BASF synthesis the presence of 9- $\mathrm{CH}_{3}$ also prevents the formation of side products.

Scheme 21. The preparation of 11-methylretinal 92 via a HWE reaction.

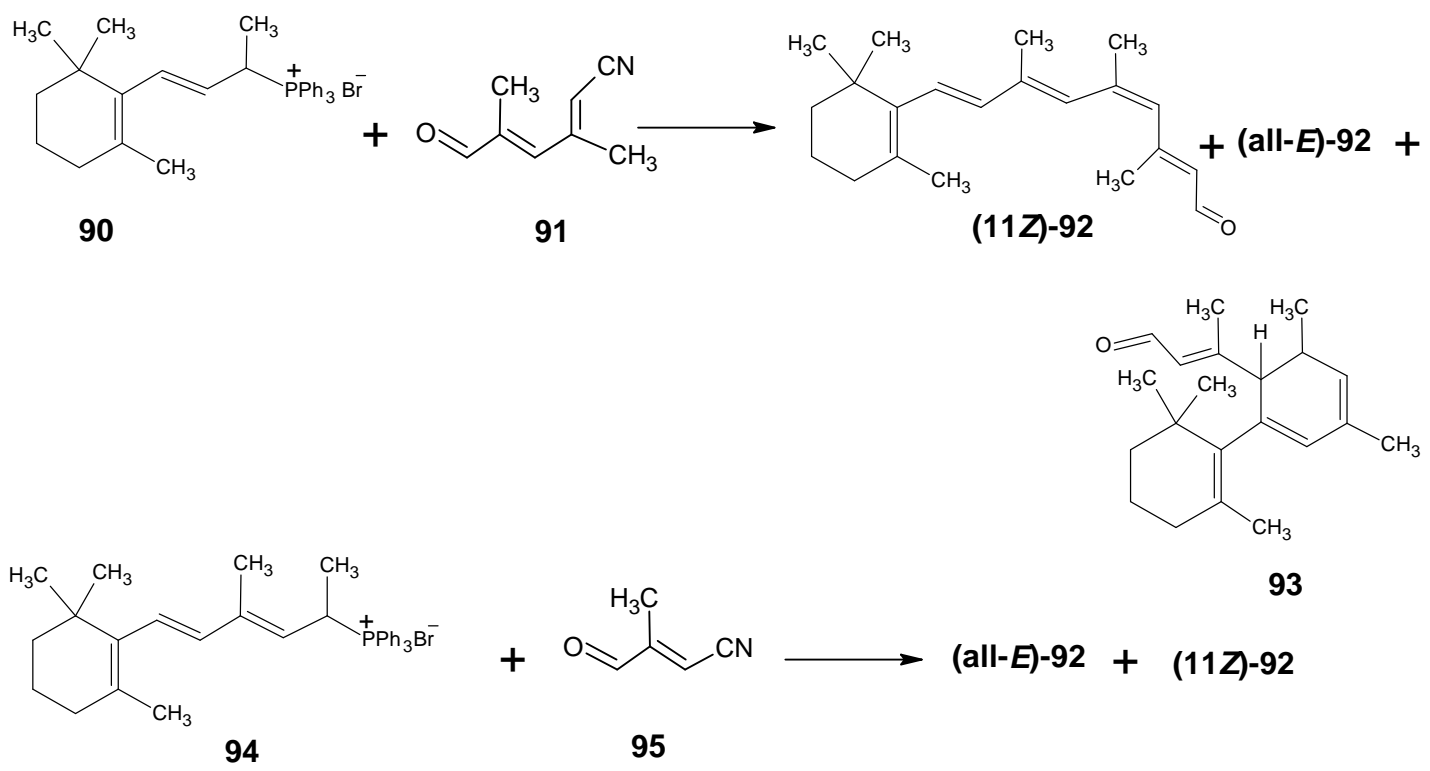

For the formation of 12-methylretinal the reactions in the Scheme 22 are used [105]. $\beta$-Ionylidene acetaldehyde 46 is coupled with the anion of methyl 2-(diethylphosphono)propionate to give the corresponding ester 96. Treatment of the ester 96 with methyl lithium and trimethylsilyl chloride gave the methyl ketone 97 which is easily extended to 12-methyl retinal 98. Methyl 2(diethylphosphono)propionate is easily obtained by a Hell-Volhardt-Zelinsky reaction on propionic acid and followed by treatment with triethylphosphite under Arbuzov condition. All carboxylic acids will give in the same way methyl 2-(diethylphosophono)carboxylates. This means that a whole series of retinals with different alkyl groups at position 12 is accessible via this method. 
Scheme 22. Preparation of 12-methylretinal 98 starting from $\beta$-ionylidene acetaldehyde $\mathbf{4 6 .}$

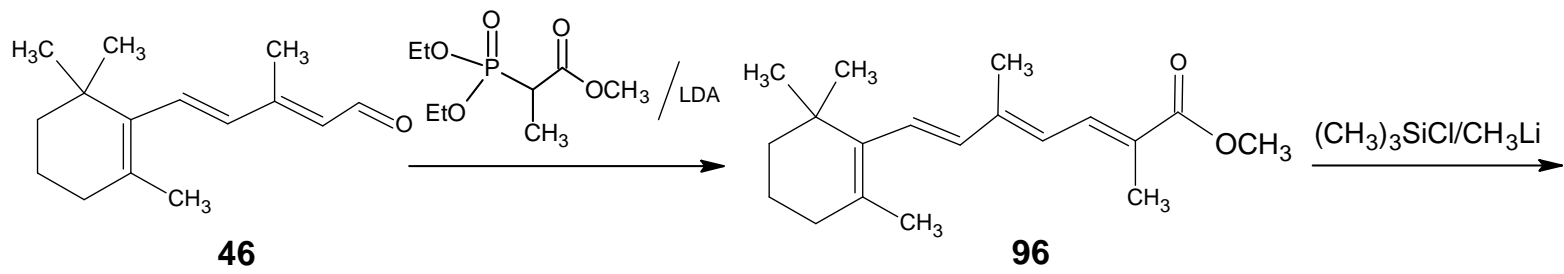

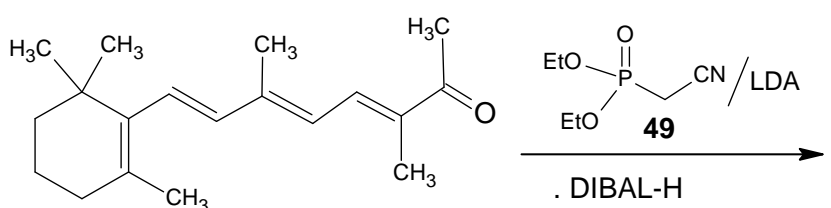

97

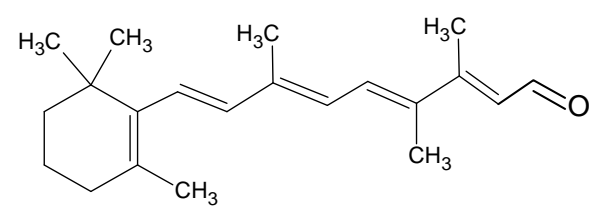

98

\subsection{Preparation of 9-demethyl-9-haloretinals and 13-demethyl-13-haloretinals}

The synthetic route depicted in Scheme 23 shows that $\beta$-ionone 17 can be easily converted into (9Z)- and all-E 9-fluoro-, 9-chloro-, 9-bromo- and 9-iodo- $\beta$-ionylidene acetaldehyde (100 and 101)[93]. The anion of $\beta$-ionone 17 is obtained by the reaction of $\beta$-ionone 17 with LDA by the removal of proton from the methyl ketone group. This anion is reacted with diethyl chlorophosphate to form the enol ether phosphate. The addition of a second equivalent of LDA gave acetylide anion by the elimination of phosphate group. The addition of one equivalent of dimethylformamide afforded a one-pot formation of the acetylene acetaldehyde 99. ${ }^{13} \mathrm{C}$-Dimethylformamide is commercially available; this means product $\mathbf{9 9}$ is accessible in any isotopically enriched form.

Treatment of product 99 with $\mathrm{LiCl}, \mathrm{LiBr}$, and $\mathrm{LiI}$ in acetic acid at $70{ }^{\circ} \mathrm{C}$ gave the complete conversion into (9Z)-9-halo- $\beta$-ionylidene acetaldehydes $100 \mathbf{b}, 100 \mathbf{c}, 100 \mathrm{~d}$ and their all- $E$ isomers, respectively. The mixtures of two $E / Z$ isomers could easily be separated by chromatography. Treatment of product 99 with commercially available tetrabutylammonium dihydrogentriflouride in 1,2-dichloroethane at $80{ }^{\circ} \mathrm{C}$ gave the two 9-fluoroderivatives $\mathbf{1 0 0 a}$ and $\mathbf{1 0 0 b}$ together with unconverted starting material 99 and product 101a and 101b. The two fluorides could easily be separated in pure form by chromatography. The chlorides $100 \mathrm{~b}$ and $\mathbf{1 0 1 b}$ are the result of the $\mathrm{F}^{-}$ion induced $\mathrm{Cl}^{-}$ion release from the 1,2-dichloroethane. The derivatives $100 \mathrm{a}, 100 \mathrm{~b}, 100 \mathrm{c}, 100 \mathrm{~d}, 101 \mathrm{a}$, 101b, 101c and 101d are converted into the 9-demethyl-9-haloretinals via a HWE reaction with the anion of the phosphonate 50. In this way the 9-fluoro-, 9-chloro-, 9-bromo-, and 9-iodoretinals are accessible in the all-E, 9Z- and 11Z-isomeric form. In a similar way it is to be expected that the $\mathrm{C}_{18}$ ketone 47 in Scheme 10 can be converted into the geometric isomers of the 13-demethyl-13haloretinals. 
Scheme 23. Preparation of (9Z)- 9-halo- $\beta$-ionylidene acetaldehyde 100a, 100b, 100c, 100d and their all- $E$ isomers 101a, 101b, 101c, 101d.<smiles>CC(=O)/C=C/C1=C(C)CCCC1(C)C</smiles>

17

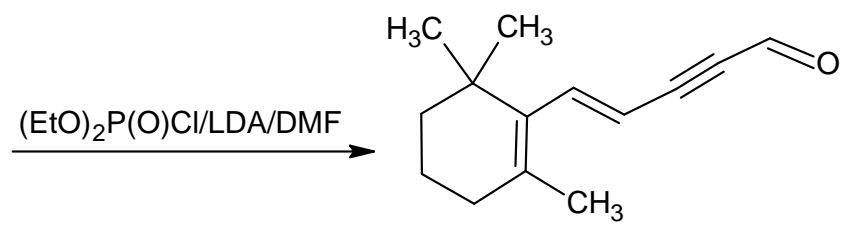

99

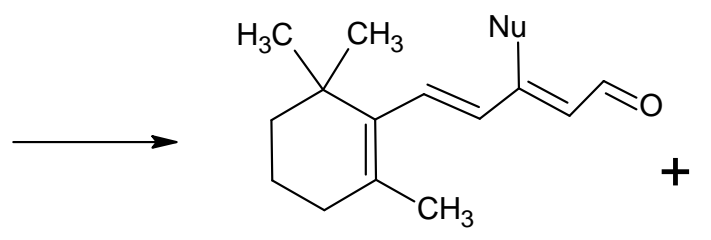

$100 \mathrm{a} \mathrm{Nu}=\mathrm{F}$

$100 \mathrm{~b} \mathrm{Nu}=\mathrm{Cl}$

$100 \mathrm{c} \mathrm{Nu}=\mathrm{Br}$

$\operatorname{100d~Nu}=I$
$101 \mathrm{a} \mathrm{Nu}=\mathrm{F}$
$101 \mathrm{~b} \mathrm{Nu}=\mathrm{Cl}$
$101 \mathrm{c} \mathrm{Nu}=\mathrm{Br}$
$101 \mathrm{~d} \mathrm{Nu}=\mathrm{I}$

\section{4. $\alpha$-Retinals via $\alpha$-Ionone}

4.1. 9-Demethyl-9-halo- $\alpha$-retinals, 9-substituted $\alpha$-retinals, 9-demethyl $\alpha$-retinal, 19,19-ethano- $\alpha$ retinal, 19,19-dimethyl $\alpha$-retinal and 12- and 14-halo substituted $\alpha$-retinals

In Scheme 24 the synthetic route is shown to prepare 4,5-didehydro-9-demethyl-9-halo-5,6dihydroretinals in the pure all-E, 9Z- and 11Z-isomer via the 9-demethyl-9-halo- $\alpha$-ionylidene acetaldehyde (112 and 113) [113]. $\alpha$-Cyclocitronitrile 72 (Scheme 18) is treated with DIBAL-H to give pure $\alpha$-cyclocitral 102. $\alpha$-Ionone 104 is obtained in pure form by the treatment of $\alpha$-cyclocitral 102 with the anion of diethyl [2-(butylimino)propyl]phosphonate 103. Usually a simple aldol condensation of $\alpha$-cyclocitral 102 with acetone 8 gave the $\beta$-ionone 17 via a base catalysed conversion but in this case pure $\alpha$-ionone 104 is obtained. The 9-methyl-9-halo- $\alpha$-ionylidene acetaldehydes $\mathbf{1 1 2 a}, \mathbf{1 1 2 b}$, 112c, 112d and 113a, 113b, 113c, 113d are obtained via the acetylene acetaldehyde 111 in the reaction sequence similar to the reactions described for $\beta$-ionylidene series in Scheme 23 . The E/Zisomers of 112 and 113 could be easily obtained in pure isomeric form. A final coupling with the anion of 50 afforded the 9-demethyl-9-halo- $\alpha$-retinals in pure all- $E$, 9Z- and 11Z-isomeric form.

$\alpha$-Cyclocitral 102 is converted into $\alpha$-ionone 104 via the HWE reaction of the anion of diethyl [2-(butylimino)propyl]phosphonate 103 (Scheme 24). The substituent $\mathrm{R}$ in phosphonate derivative is varied to obtain phosphonate derivatives 105, 107 and 109 which gave $\alpha$-ionone derivatives without a keto methyl group 106, with a cyclopropyl group 108 and an isopropyl group 110, respectively. For HWE reagents $(\mathbf{1 0 3}, \mathbf{1 0 5}, 107$ and 109) imines of the carbonyl compound in question are prepared. The anion of the imine (prepared by the addition of an equivalent of LDA) is treated with one equivalent of diethyl chlorophosphate to obtain a phosphonate derivative. By the additional equivalent of LDA to the phosphonate derivative phosphonate carbanion is generated in situ, final nucleophilic addition of the carbanion onto the $\alpha$-cyclocitral 102 gave the corresponding $\alpha$-ionone derivative. 
Interestingly, such a process did not work in the Peterson olefination strategy [114]. Treatment of the anion of ketimine with trimethylsilyl chloride leads to N-silylation whereas in the preparation of phosphonate derivative only $\mathrm{C}$-phosphonylation takes place. It is clear that the Peterson reagent $N$-[2-(trimethylsilyl)ethylidene]methamine used in Scheme 10 is an exception where the presence of sterically bulky group forces the silylation on the carbon atom.

Scheme 24. Preparation of $\alpha$-ionylidene acetaldehydes (halogen substituted at position 9) 112 and 113 starting from $\alpha$-cyclocitral 102. Substituent $\mathrm{R}$ in phosphonate is varied to obtain the chemically modified $\alpha$-ionones 106,108 and 110 .
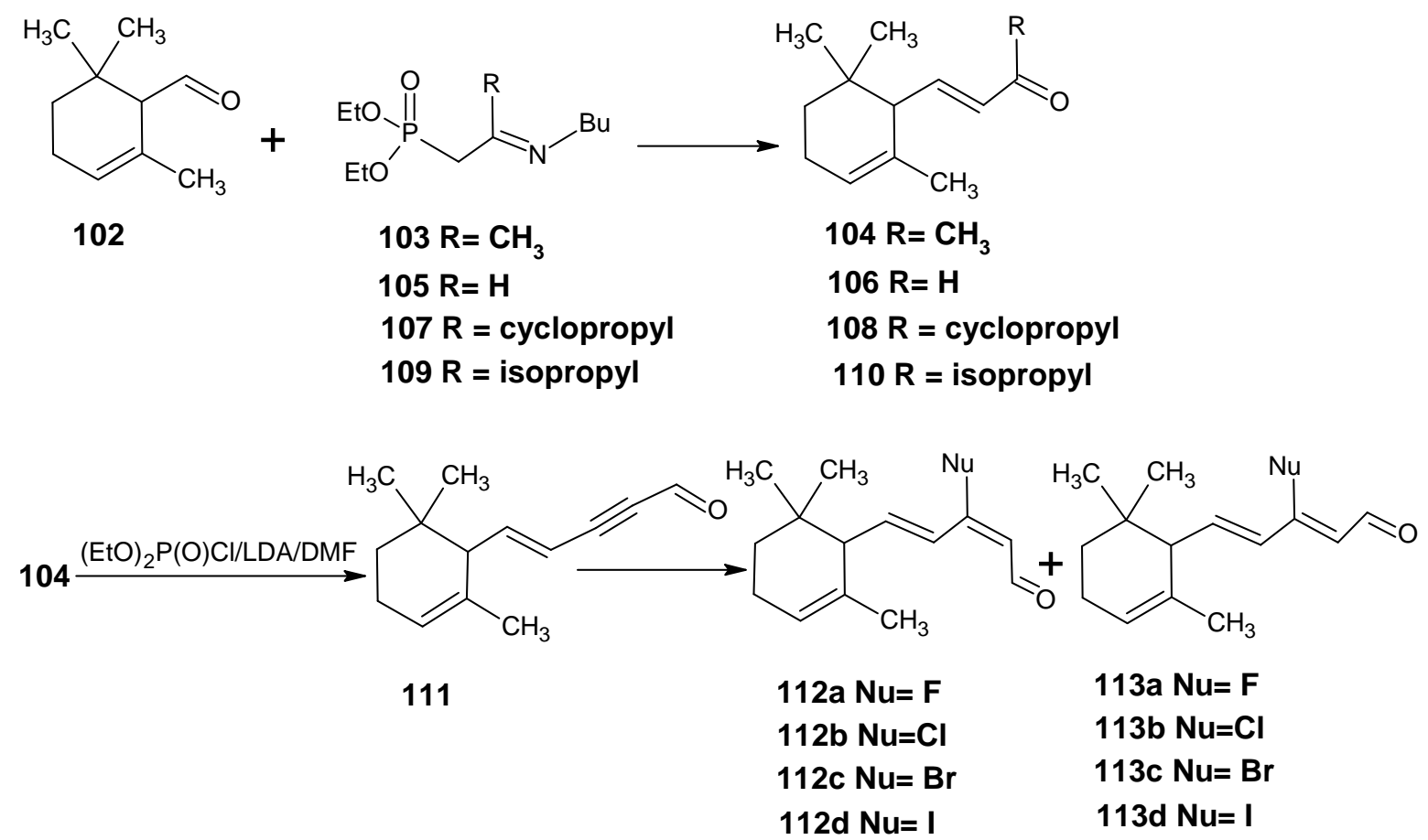

The $\alpha$-ionones that are prepared via the synthetic route in Scheme 24 did not show any trace of the corresponding $\beta$-ionones. These $\alpha$-ionones could easily be converted into the corresponding 9 -substituted $\alpha$-retinals in all- $E$, 9Z-, $11 Z$-isomeric form. It is clear that besides the prepared $\alpha$-retinal a whole series of 9-substituted $\alpha$-retinals will be accessible via the reactions depicted in Scheme 24 . In this way besides 9-substituted $\alpha$-retinals also 9-demethyl- $\alpha$-retinal, 19,19-ethanoretinal and 19,19dimethyl- $\alpha$-retinal via phosphonate derivatives 105, 107 and 109, respectively are prepared [106,113]. For the preparation of phosphonate derivatives 107 and 109 methyl cyclopropyl ketone and methyl isopropyl ketone, respectively are used. These building blocks are not commercially available in stable isotopically labeled form. However, they can be prepared by using commercially available isotope enriched starting materials via simple reactions mentioned in the schemes.

The $\alpha$-retinals discussed in this paper are accessible in any isotope enriched form. The corresponding $\beta$-ionone derivatives can easily be prepared in pure form via the similar method described in Scheme 17 starting from $\beta$-cyclocitral 51. The $\beta$-ionones so prepared can easily be converted into the corresponding retinals with different substituents at the position 9 in all-E, $9 Z$ - and $11 Z$-isomeric form. But in the case of the base catalyzed aldol condensation of $\beta$-cyclocitral $\mathbf{5 1}$ with methyl isopropyl ketone and methyl cyclopropyl ketone mixtures of the $\alpha$ - and $\beta$-ionone derivatives 
are obtained which are very difficult to separate in pure form. It is clear that the strategy discussed so far gives an access to many substituted retinals and their $\alpha$-isomers with substituents on various positions and full access to any stable isotopically enriched form.

Another approach to obtain modified retinals is via the chemical modification of the 4-(diethylphosphono)-3-methylbut-2-enenitrile 50 and its diphenyl homologue 4-(diphenylphosphono)3-methylbut-2-enenitrile 114. The chemical modification of phosphonate $\mathbf{1 1 4}$ is mentioned in Scheme 25. Treatment of phosphonate derivative $\mathbf{1 1 4}$ with base gave phosphonate carbanion which reacted with electrophilic reagents such as selectfluor, NCS, NBS, NIS and trimethylsilylchloride to give the corresponding products 115-119 with the substitution exclusively at position 2 with respect to the nitrile function [106]. The phosphonate group directs the incoming electrophile towards the $\gamma$-position with respect to itself [115]. Similarly, nitrile function directs the incoming electrophile towards the $\alpha$-position with respect to itself.

Scheme 25. The chemical modification of 4-(diphenylphosphono)-3-methylbut-2enenitrile 114 to prepare 12- and 14-halo substituted retinals and $\alpha$-retinals in the all- $E$, and $11 Z$-isomeric form.
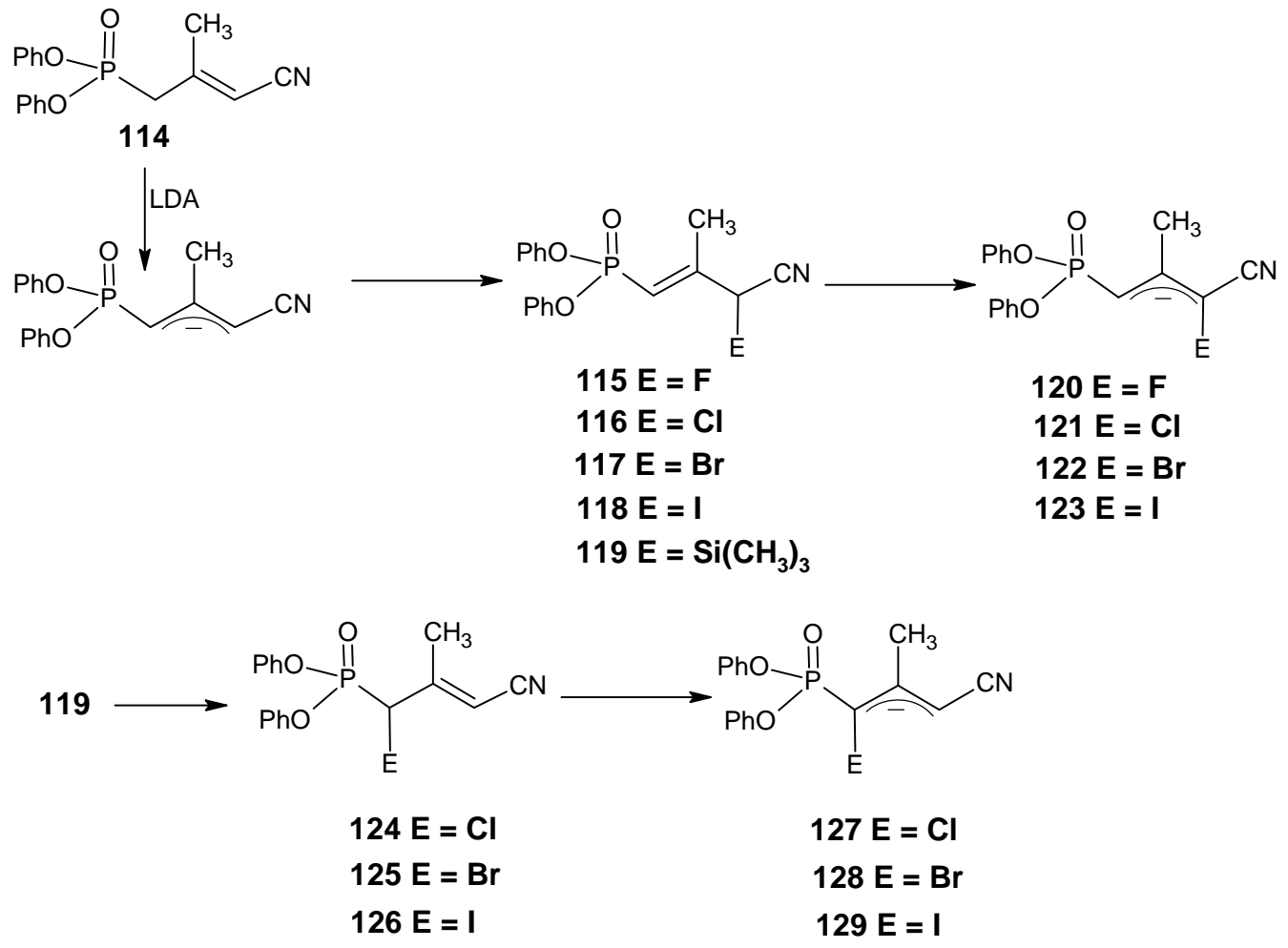

However, electrophilic substitution in the phosphonate $\mathbf{1 1 4}$ is achieved at position 4 by using the trimethylsilyl as a temporary leaving group. The silylderivative $\mathbf{1 1 9}$ is treated with NCS, NBS and NIS to give the products 124-126 with halogen substitution at position 4. However, the silylderivative 119 didn't react with selectfluor [106]. The anion of the corresponding phosphonate derivative 120, 121, 122 and 123 is coupled with $\beta$-ionylidene acetaldehyde 46 to give (11E/11Z)-14-haloretinals. Similarly, the coupling of the anion of the corresponding phosphonate derivatives 127, 128 and 129 with $\beta$-ionylidene acetaldehyde $\mathbf{4 6}$ gave (11E/11Z)-12-haloretinals. 
Similarly, phosphonate $\mathbf{5 0}$ is converted into substituted phosphonate reagents by the substitution reactions described above. These reagents under the right conditions led to pure retinals and $\alpha$-retinals with the newly formed carbon 11-carbon 12 double bond in the $E$-configuration. Coupling of the HWE reagents depicted in Scheme 24 with either $\beta$-cyclocitral 51 or $\alpha$-cyclocitral 102 led to $\beta$ - and $\alpha$-ionylidene acetaldehydes, respectively with substitution at position 8 or 10 (Scheme 20). Furthermore, treatment of these chemically modified $\alpha$ - and $\beta$-ionylidene acetaldehydes again with the reagents in Scheme 25 will result in retinals and their $\alpha$-isomer chemically modified at positions 8,10 , 12 and 14 and all possible combination of modifications at these positions. All these novel systems are also accessible in any stable ${ }^{13} \mathrm{C}$ labeled form.

\section{Nor-Retinals}

\subsection{6,17,18-Trinor-retinal, 16,17-dinor-retinal and 16-nor-retinal}

The synthetic routes depicted in Scheme 26 show that the $\beta$-cyclocitral derivatives are prepared starting from cyclohexanone derivatives. Cyclohexanone $\mathbf{1 3 0}$ is formylated with ethyl formate in the presence of base via the reactions in Scheme 26 [116].

Scheme 26. Conversion of cyclohexanone $\mathbf{1 3 0}$ into $\beta$-cyclocitral derivatives.
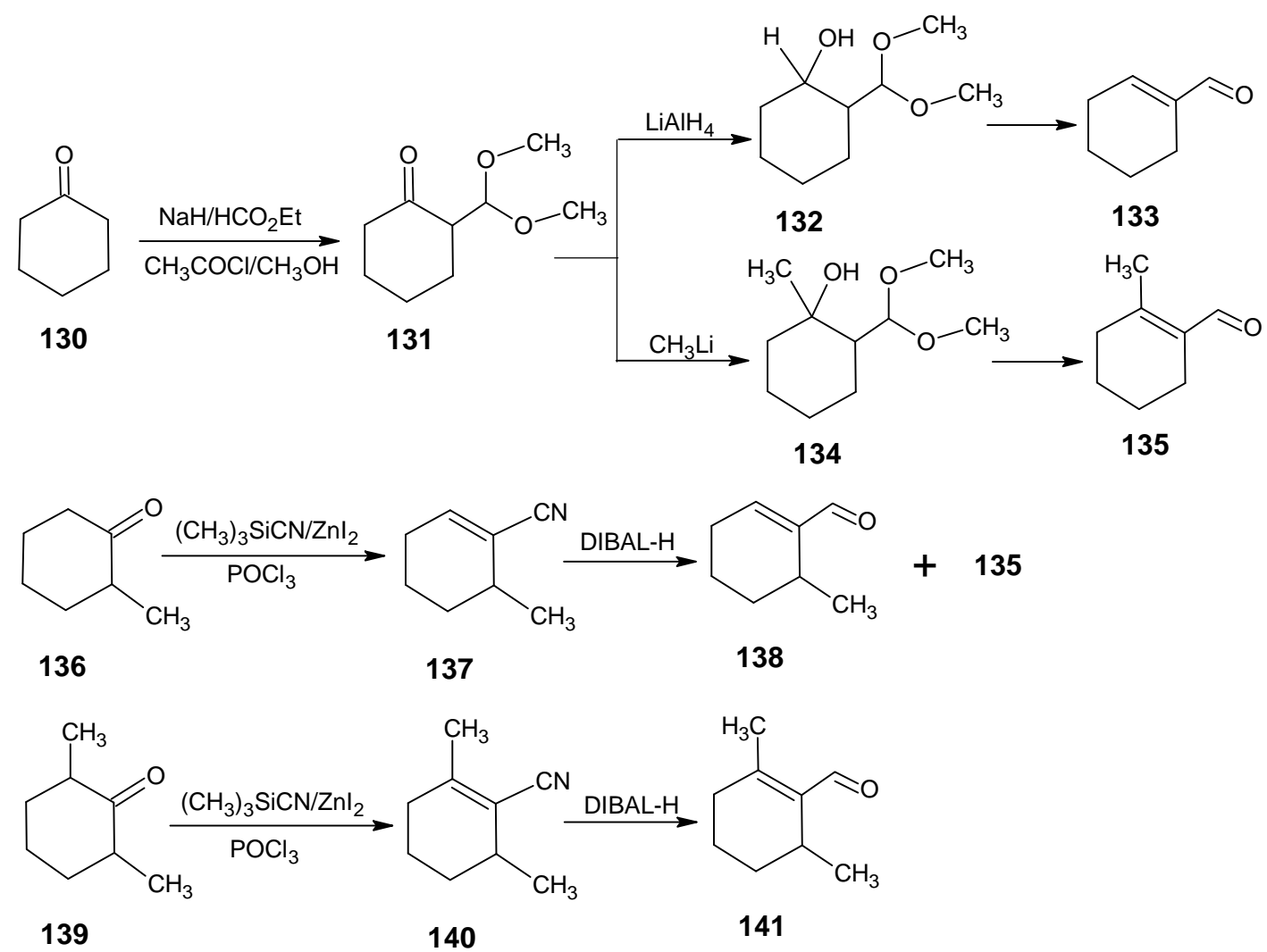

The formylated cyclohexane derivative is treated with acetyl chloride and subsequently treated with methanol in the presence of acid to obtain the corresponding acetal 131. Upon treatment with $\mathrm{LiAlH}_{4}$ the carbonyl function is reduced to alcohol 132, the acid catalyzed deprotection of acetal function and elimination of a water molecule afforded cyclohex-1-en-1-al 133. 
Similarly, reaction of the product $\mathbf{1 3 1}$ with methyl lithium followed by an acid catalyzed deprotection of acetal function and the elimination of a water molecule afforded 2-methylcyclohex-1en-1-al 135. The chain extension on these products 133 and 135 are carried out by the reaction of each with phosphonate 50 (Scheme 11) twice to afford 16,17,18-trinor-retinal and 16,17-dinor-retinal, respectively.

2-Methylcyclohexanone $\mathbf{1 3 6}$ is treated with trimethylsilyl cyanide and subsequent removal of water gave 6-methylcyclohex-1-en-nitrile 137 (mixed with other isomer). After DIBAL-H reduction of the product 137 6-methylcyclohex-1-en-1-al 138 is easily separated from the isomeric product $\mathbf{1 3 5}$. Similarly, starting from 2,6-dimethylcyclohexanone 139 2,6-dimethylcyclohex-1-en-1-al 141 is obtained. These two aldehydes 138 and 141 are easily converted into 16,17-dinor-retinal and 16-nor-retinal, respectively.

In Scheme 27 it is shown that 6,6-dimethylcyclohex-1-en-1-al 146 is prepared starting from methyl 7-methyl-3-oxo-oct-6-enoate 142 [117]. The keto ester 142 upon treatment with $\mathrm{SnCl}_{4}$ afforded cyclohexanone ester 143 followed by $\mathrm{NaBH}_{4}$ reduction and the removal of a water molecule to obtain cyclohexene ester 144. $\mathrm{LiAlH}_{4}$ reduction and subsequent $\mathrm{MnO}_{2}$ oxidation of the product 144 gave $\beta$-cyclocitral derivative 146. The aldehyde 146 via above mentioned procedure is converted into 5-demethylretinal.

Scheme 27. Preparation of 6,6-dimethylcyclohex-1-en-1-al 146 starting from methyl 7methyl-3-oxo-6-octenoate 142.

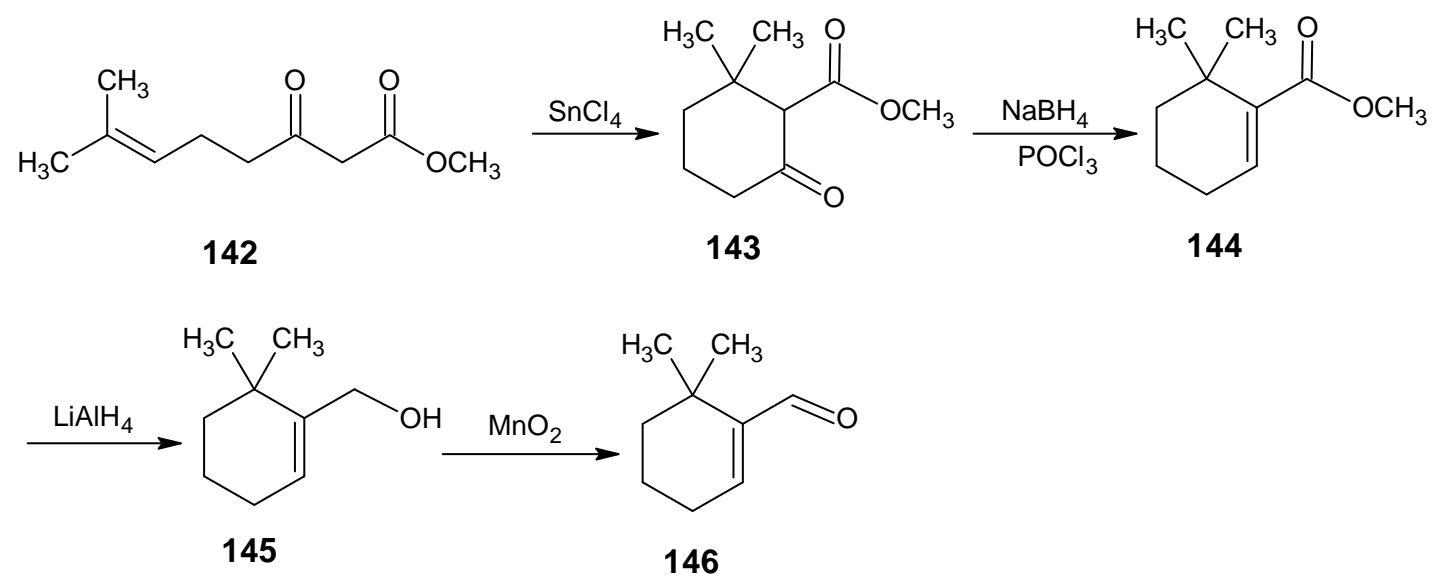

In Scheme 28 it is depicted that the commercial nitroxide product 147 can be converted into the $N$-methoxy- $N$-methyl amide derivative and subsequent DIBAL-H reduction into the spin label 148 [118]. The cyclocitral derivative 149 could be prepared in a similar way. Both products 148 and 149 could be converted into the corresponding retinals by adjusting the HWE reagent $\mathbf{5 0}$ (Scheme 11) into the corresponding esters. After the HWE coupling the corresponding conjugated esters are obtained which are converted into the corresponding $N$-methoxy- $N$-methyl amide derivatives. DIBAL-H reduction of these amides gave the corresponding aldehydes. However, DIBAL-H reduction of the conjugated nitriles obtained via the reaction of phosphonate $\mathbf{5 0}$ didn't give useful results in the case of the nitroxyl and the corresponding amide containing system. 
Scheme 28. Preparation of nitroxide aldehyde 148 and the corresponding pyrroline aldehyde 149.

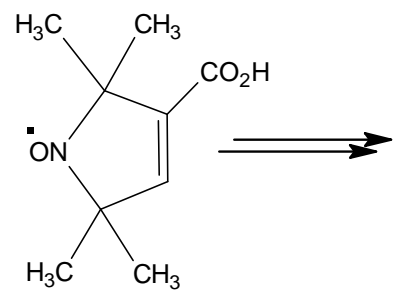

147

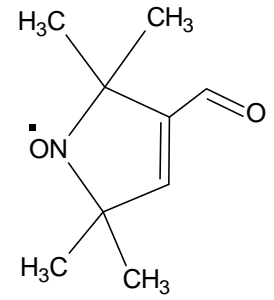

148<smiles>CC1=C(C=O)C(C)(C)NC1(C)C</smiles>

149

\section{Bridged and Demethyl Retinals}

6.1. DL-8,16-Methanoretinal, 8,18-methanoretinal, (R)-5-demethyl-8,16-methanoretinal, 1,5didemethyl-8,16-methanoretinal, 1,1-didemethyl-8,18-methanoretinal, 1,1-didemethyl-18-didehydro8,18-methanoretinal

The starting $\beta$-ionone derivatives 153 and 159 needed to prepare DL-8,16-methanoretinal and 8,18-methanoretinal, respectively are obtained via the synthetic routes mentioned in Schemes 29 and 30 [119]. 2,6-Dimethylcyclohexanone $\mathbf{1 5 0}$ is converted into racemic bicyclic enone $\mathbf{1 5 1}$ via a Robinson annulation reaction with methylvinyl ketone. Upon treatment with the acetylide anion the tertiary propargylic alcohol $\mathbf{1 5 2}$ is obtained. Treatment of the alcohol $\mathbf{1 5 2}$ with formic acid gave a conjugated acetylene derivative (not shown in the Scheme 29) by the removal of water molecule and subsequent addition of water on the triple bond in the presence of acid afforded the racemic $\beta$-ionone derivative 153.

Scheme 29. Preparation of racemic $\beta$-ionone derivative 153 starting from 2,6dimethylcyclohexanone $\mathbf{1 5 0 .}$

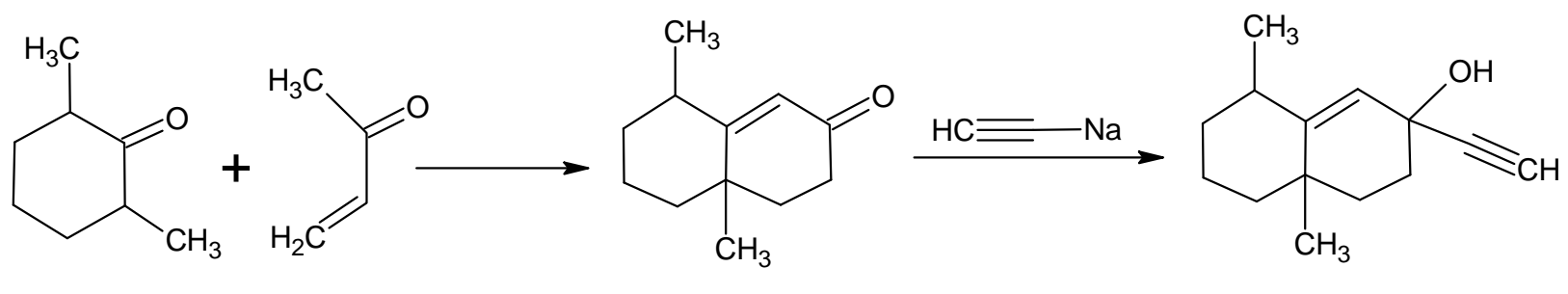

150

151

152<smiles>CC(=O)C1=CC2=C(C)CC(C(=O)O)CCC2(C)CC1</smiles>

153

8,16-Methanoretinal 
Scheme 30. Preparation of bicyclic $\beta$-ionone 159 starting from myrcene 154.

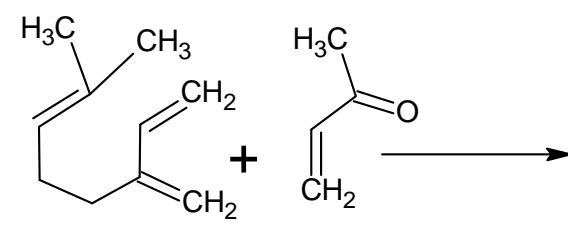

154<smiles>CC(=O)C1CC=C(CCC=C(C)C)CC1</smiles>

155<smiles>CC(=O)C1CCC=C(CCC=C(C)C)C1</smiles>

156<smiles>CC(=O)C1=CC=C(CC/C=C(/C)C(=O)[O-])CC1</smiles><smiles>CC(=O)C1=CC2=C(CCCC2(C)C)CC1</smiles>

159

The commercially available myrcene $\mathbf{1 5 4}$ underwent a Diels-Alder reaction with methylvinyl ketone to give a mixture of two Diels-Alder products 155 and 156. Treatment of these products with $\mathrm{SO}_{2} \mathrm{Cl}_{2}$ chlorinated the tertiary carbon next to the carbonyl function. Elimination of $\mathrm{HCl}$ via the reaction with DBN gave cyclohexadienones 157 and 158. These products are separated easily. Treatment of product $\mathbf{1 5 7}$ with sulfuric acid afforded the bicyclic $\beta$-ionone $\mathbf{1 5 9}$ which is further converted into the corresponding 8,18-methanoretinal.

In Scheme 31 the synthetic route is depicted to show that the commercially available $(R)$-bicyclic ketone 160 is converted into a $\beta$-ionone derivative 162 [120]. Reaction with trimethylsilyl cyanide in the presence of zinc iodide and the elimination of a molecule of water gave the conjugated nitrile 161. Treatment of the later with methyl lithium afforded the $(R)$ form of the $\beta$-ionone derivative $\mathbf{1 6 2}$. That can be further converted into $(R)$-5-demethyl-8,16-methanoretinal. Also, the corresponding $\mathrm{S}$ form of bicyclic ketone is commercially available. Similarly, following the reactions described above (S)-5demethyl 8,16-methanoretinal is obtained via the intermediate $(S)$ form of the $\beta$-ionone derivative. In the same paper racemic 5-demethyl-8,16-methanoretinal with deuterium incorporation at positions 5 and 7 have been described starting from 2-methylcyclohexanone (Scheme 29).

In the lower line of Scheme 31 the synthetic route is given to show that 2-methoxynaphthalene $\mathbf{1 6 3}$ is converted into the $\beta$-ionone derivative 166 [121]. Birch reduction of $\mathbf{1 6 3}$ gave 1,4,5,8-tetrahydro-2methoxynaphthalene which upon treatment with acid afforded the bicyclic ketone 164. The product 164 is treated with trimethylsilyl cyanide and subsequent $\mathrm{HCl}$ treatment gave the cyanohydrin via desilylation. The later product is treated with triethylsilane and trifluoroacetic acid. The carbinol is 
converted into the carbenium ion, which is reduced with triethylsilane into the bicyclic nitrile $\mathbf{1 6 5}$. Treatment of the product $\mathbf{1 6 5}$ with methyl lithium afforded the $\beta$-ionone derivative $\mathbf{1 6 6}$. The product 166 is converted into (RS)-1,5-didemethyl-8,16-methanoretinal.

Scheme 31. Preparation of $\beta$-ionone derivatives 162 and 166 from starting from $(R)$ bicyclic ketone 160 and 2-methoxynaphthalene 163, respectively.

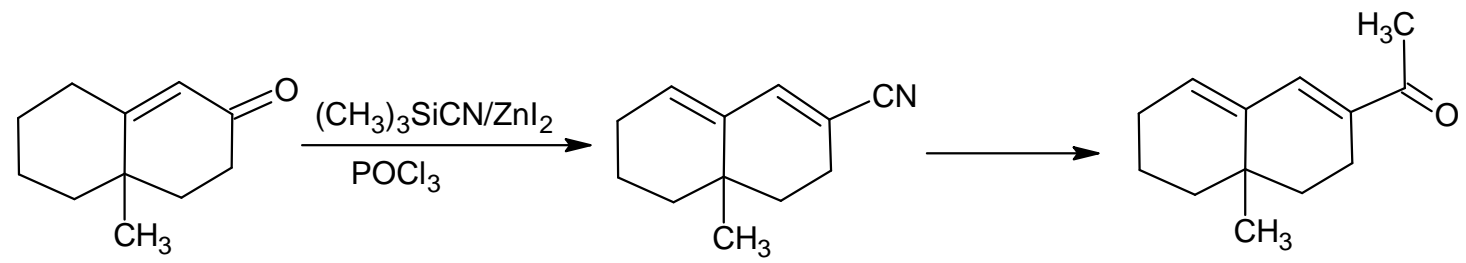

160

161

162<smiles>COc1ccc2ccccc2c1</smiles>

163<smiles>CC[SiH3][SiH3]Cl</smiles>

164<smiles>N#CC1=CC2=CCCCC2CC1</smiles>

165<smiles>CC(=O)C1=CC2=CCCCC2CC1</smiles>

166

In Scheme 32 the synthetic route is shown for the preparation of $\beta$-ionone derivatives 168 and 169. Diels-Alder reaction of 1,2-bis(methylene)-cyclohexane $\mathbf{1 6 7}$ and 3-bromobut-3-en-2-one and subsequent $\mathrm{HBr}$ elimination afforded the $\beta$-ionone derivative 168. Oxidation of the product 168 with DDQ gave the aromatic $\beta$-ionone derivative 169. The $\beta$-ionone derivatives 168 and 169 could easily be converted into all-E 1,1-didemethyl-8,18-methanoretinal and 1,1-didemethyl-18-didehydro-8,18methanoretinal, respectively [121].

Scheme 32. Preparation of $\beta$-ionone derivative 168 and its aromatic counterpart 169.<smiles>C=C(Br)C(=C)C(C)=O</smiles>

167<smiles>CC(=O)C1=CC2=C(CC1)CCC(CC(=O)O)CC2</smiles>

168
169 
6.2. 11,19-10,20-Dimethanoretinal, 10,20-methanoretinal, 13-demethyl-10,12-ethanoretinal, 13demethyl-12,14-ethanoretinal, 13-demethyl-10,12-propanoretinal and 13-demethyl-12,14propanoretinal

In Scheme 33 the synthetic route is depicted to show the conversion of $\beta$-ionone $\mathbf{1 7}$ into $\mathrm{C}_{20}$ ketone 175 and $\mathrm{C}_{19}$ ketone 177 [122]. $\beta$-Ionone $\mathbf{1 7}$ is alkylated with ethyl iodoacetate in the presence of a base to give a keto ester 170. A HWE reaction of the keto ester 170 with the cyanophosphonate 171 afforded the conjugated nitrile 172. Product $\mathbf{1 7 1}$ is easily accessible from the commercially available 5-chloropentan-2-one. Treatment of the product 172 with t-butanolate base afforded the product 173 which in the presence of the acid gave the diketone 174. Aldol condensation of the product 174 afforded the locked enone system 175 which is converted into 11,19-10,20-dimethanoretinal. In the lower line of the Scheme 33 it is shown that a HWE coupling of $\beta$-ionone $\mathbf{1 7}$ and cyanophosphonate 171 afforded the conjugated nitrile 176. Further DIBAL-H reduction followed by the acetal deprotection of the product $\mathbf{1 7 6}$ and subsequent aldol condensation led to a locked $\mathrm{C}_{19}$ ketone derivative 177. The product 177 has been converted into 10,20-methanoretinal into the (10,13 all-E)-, $(10 Z, 13 E)-,(10 E, 13 Z)$ - and $(10 Z, 13 Z)$-isomers which could be simply isolated in pure form.

Scheme 33. Reaction of $\beta$-ionone 17 leading to the $C_{20}$ ketone 175 and $C_{19}$ ketone 177.
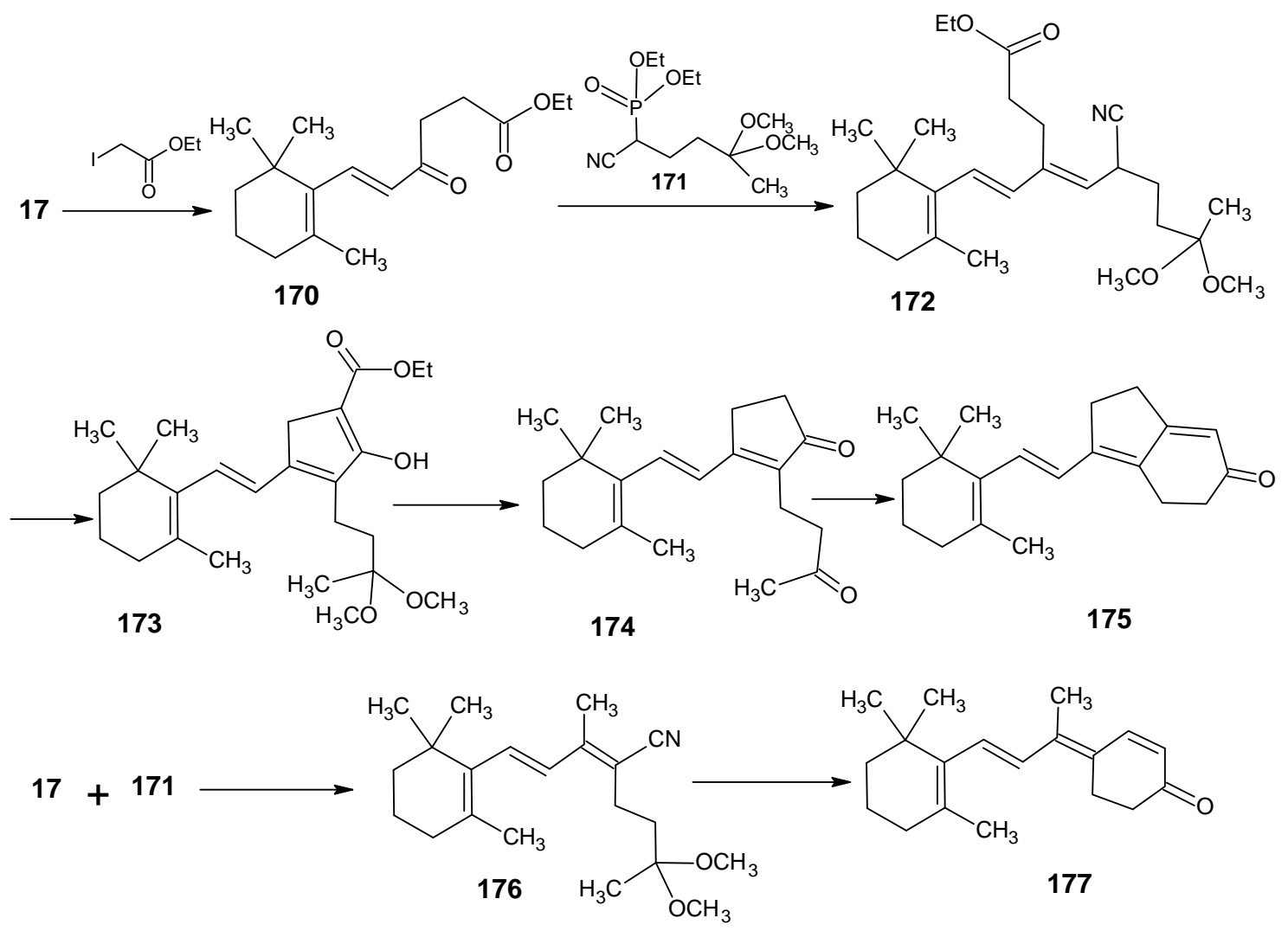

In Scheme 34 the synthetic route is depicted to show the conversion of 1,4-dicyanobutane to the HWE reagent cyanophosphonate $\mathbf{1 7 8}$ by the reaction of 2 equivalents of LDA and one equivalent of diethyl chlorophosphate [123]. This reagent can be used to introduce ethano-bridge in the retinal structure. Similarly, the HWE reagent 179 can be prepared from 1,5-dicyanopentane. With the cyanophosphonate $\mathbf{1 7 9}$ propano-bridged retinals can be prepared. 
Scheme 34. Nitrile phosphonates 178 and 179 which are used to prepare of 13-demethyl10,12-ethanoretinal 181 and 13-demethyl-12,14-ethanoretinal 184 and their corresponding propano- derivatives.

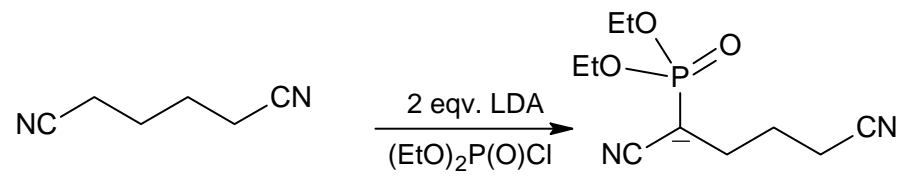

178

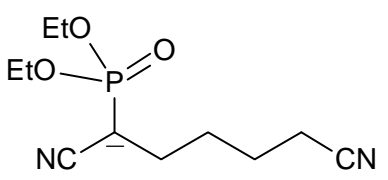

179

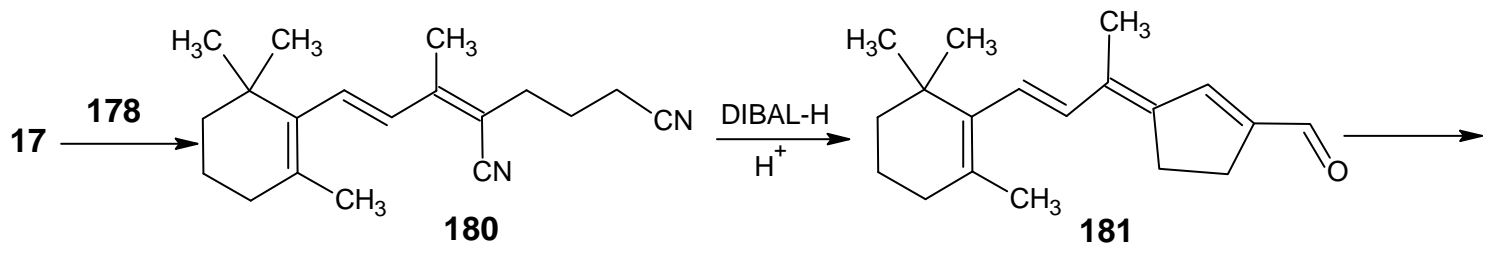<smiles>COC(=O)C1=CC(=C(C)C)CC1</smiles>

182<smiles>CC(C=CC1=C(C)CCC(C=[18O])C1(C)C)=CC=C1C=C(C=O)CC1</smiles>

184

The reaction of $\beta$-ionone 17 and cyanophosphonate 178 afforded the dinitrile 180. DIBAL-H reduction and aldol condensation gave the product 181 . The product 181 can be easily converted into the ester 182. The later upon treatment with methyl lithium in the presence of trimethylsilyl chloride gave the methyl ketone 183. The later can easily be converted into 13-demethyl-10,12-ethanoretinal. Similarly, by the reaction of $\beta$-iononylidene acetaldehyde 46 and cyanophosphonate 178 13-demethyl12,14-ethanoretinal 184 is obtained. By repeating the reactions depicted in Scheme 34 with the reagent 179 13-demethyl-10,12-propanoretinal and 13-demethyl-12,14-propanoretinal are accessible.

\subsection{3-Demethyl-10,14-thiaretinal and 11,14-bridged 13-demethyl retinals}

In Scheme 35 the synthetic route is depicted to show the conversion of the $\alpha-\mathrm{C}_{14}$ aldehyde 185 (an isomer of the product $\mathbf{2 1}$ in Scheme 3) into the thiaretinal 188. The product $\mathbf{1 8 5}$ is treated with dibromomethyltriphenyphosphorane to give dibromoethene derivative. Debromination by butyl lithium afforded the corresponding acetylene derivative. Treatment of the product with 4,4dimethoxybut-2-yn-1-al gave the diacetylene alcohol 186 [124]. $\mathrm{MnO}_{2}$ oxidation of the product 186 led to a ketone which is treated with thiourea to give the thiopyranone $\mathbf{1 8 7}$. Treatment of the product 187 with DIBAL-H and subsequent deprotection of the acetal function afforded 9Z-derivative $\mathbf{1 8 8}$ and its all- $E$ isomer which could easily be separated. 
Scheme 35. Preparation of (9Z)-13-demethyl-10,14-thiaretinal from $\alpha-C_{14}$ aldehyde 185 and its all- $E$ isomer (not indicated in the scheme).<smiles>CC1=C(/C=C/C(C)C=O)C(C)(C)CCC1</smiles>

185<smiles>COC(C)C#CC(O)C#CC(C)C=CC1=C(C)CCCC1(C)C</smiles><smiles>COC(OC)c1cc(=O)cc(C(C)/C=C/C2=C(C)CCCC2(C)C)s1</smiles>
187<smiles>CC1=C(/C=C/C(C)=C2/C=CC=C(C=O)S2)C(C)(C)CCC1</smiles>

188

In Scheme 36 the synthetic route is depicted to show the reaction of $\beta$-ionyl triphenylphosphonium bromide 90 (Scheme 21) with aromatic dialdehydes 189 a-e to obtain a mixture of all- $E$ and $11 Z$ bridged retinals 190 a-e [125]. The Wittig reaction is very selective by reacting only one aldehyde function of the dialdehydes $\mathbf{1 8 9}$ to give all- $E$ and 11Z-products as it has been described in BASF technical syntheses. The Wittig reaction showed further selectivity with 3-methylpyrrole-2,5dialdehyde 191 affording only $11 Z$ and all- $E$ mixture of 11,14-iminoretinal 192.

Scheme 36. Preparation of 11,14-bridged 13-demethyl retinals 190 a-e [a $(X=N H)$, b $\left.\left(\mathrm{X}=\mathrm{N}-\mathrm{CH}_{3}\right), \mathbf{c}(\mathrm{X}=\mathrm{S}), \mathbf{d}(\mathrm{X}=-\mathrm{CH}=\mathrm{CH}-), \mathbf{e}(\mathrm{X}=\mathrm{O})\right]$.<smiles>CC1=C(/C=C/C(C)[Pb]Br)C(C)(C)CCC1</smiles>

90<smiles>[X]c1ccc(C=O)cc1/C=C(C)/C=C/C1=C(C)CCCC1(C)C</smiles>

189 190 a,b,c,d,e<smiles>CC1=C(/C=C/C(C)=C/c2cc(C)c(C=O)[nH]2)C(C)(C)CCC1</smiles>

\subsection{9-Demethyl retinal, 13-demethyl retinal and 9,13-didemethyl retinal}

For the preparation of 9-demethyl-, 13-demethyl- and 9,13-didemethyl retinals the reactions in Scheme 6 for BASF preparation of vitamin A have been modified [126]. In Scheme 37 the synthetic route is depicted to show that $\beta$-ionone $\mathbf{1 7}$ is condensed with ethyl formate under basic conditions. The 
resulting aldehyde is converted into acetal 194. Upon $\mathrm{LiAlH}_{4}$ reduction and deprotection afforded the conjugated aldehyde 195. Mild $\mathrm{NaBH}_{4}$ reduction, followed by the reaction with $\mathrm{HBr}$ and phosphine gave phosphonium salt 196. Commercial cis-butenediol was partially acetylated into the monoacetate 197. Upon oxidation with pyridinium chlorochromate the conjugated aldehyde 198 is obtained.

Scheme 37. Preparation of 9,13-didemethyl retinyl acetate 199 via the HWE reaction of phosphonium bromide 196 and the conjugated acetate aldehyde 198.
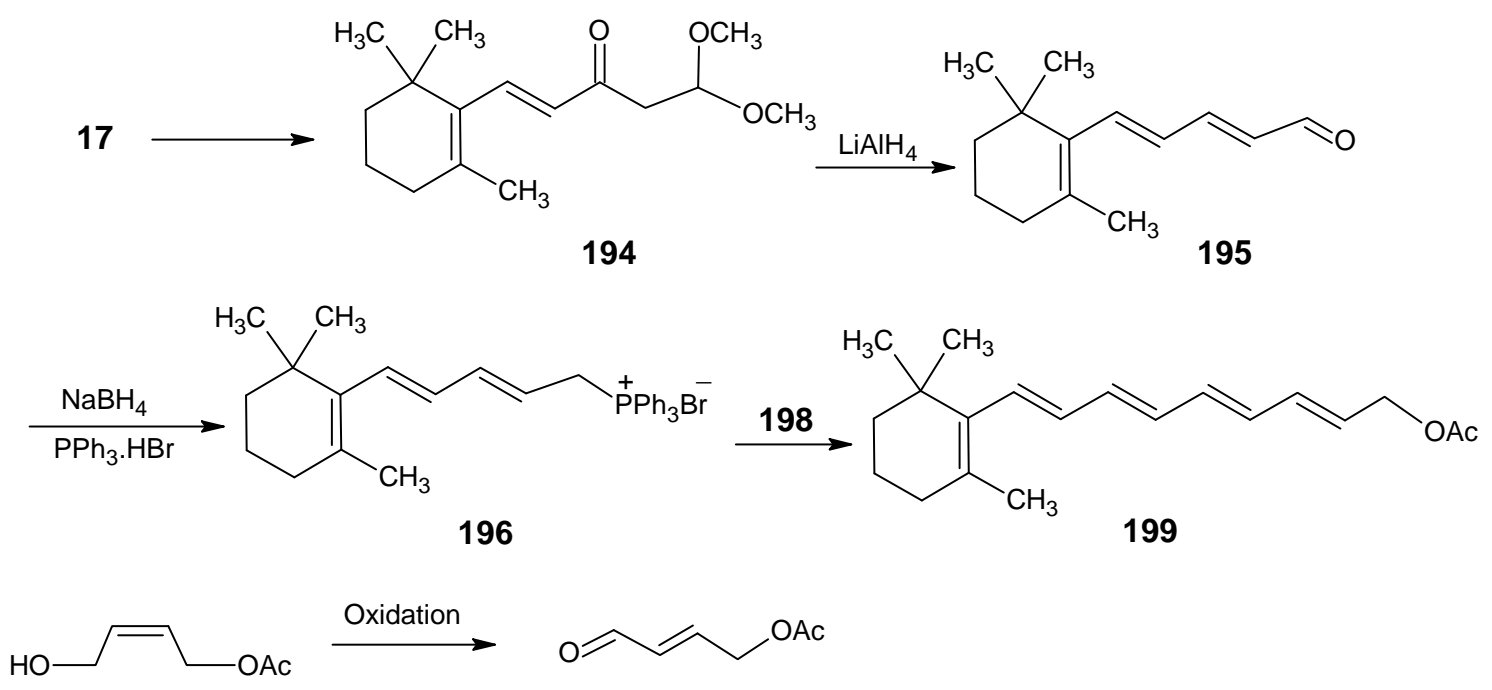

197

198

The HWE reaction of phosphonium bromide 33 (Scheme 6) with the acetate aldehyde 198 gave a mixture of (11Z)- and all-E 13-demethyl retinyl acetate. The HWE reaction of phosphonium bromide 196 with the acetate aldehyde 35 (Scheme 6) gave a mixture of (11Z)- and all-E 9-demethyl retinyl acetate. The condensation of the phosphonium bromide 196 and the acetate aldehyde 198 afforded 9,13-didemethyl retinyl acetate 199 in $11 Z$ and all- $E$ forms. 9- and 13-Demethyl retinals in various deuterium enriched forms have been described [127].

\section{Conclusions}

In this paper the contributions of the Leiden group to the site directed stable isotope enrichment in natural retinoids and chemically modified retinoids has been reviewed. It is clear that a modular approach to the Wittig chemistry on nitrile reagents provides access to any chemically modified retinoid isotopomer. Modifications in the synthetic schemes and easy modifications in the building blocks give simple access to any isotopomer of retinoids in a rational way. We dedicate this paper to the future investigators who will develop the field of stable isotope enriched retinoids, prepare the now accessible isotopomers and related compounds further in a fundamental way to explore the various aspects of the role of vitamin A in (human) life leading to an ever deeper understanding of the bio(chemistry) of retinoids. 


\section{Acknowledgments}

The authors are thankful to the organizations that supplied the financial resources to carry out this work. This paper has been written with great indebtedness to the investigators in the Leiden group and worldwide whose contributions have been essential to the work described in this review.

\section{References}

1. Stepp, W. Versuche über Fütterung mit lipoidfreier Nahrung. Biochem. Zeitschrift 1909, 22, $452-460$.

2. Osborne, T.B.; Mendel, L.B. The influence of butter fat on growth. J. Biol. Chem. 1913, 16, 423-437.

3. Steenbock, H. White corn vs. yellow corn and a probable relation between the fat-soluble vitamine and yellow plant pigments. Science 1919, 50, 352-353.

4. Khachik, F. Analysis of carotenoids in nutritional studies. In Carotenoids Volume 5: Nutrition and Health; Britton, G., Liaaen-Jensen, S., Pfander, H., Eds.; Birkhauser Verlag: Basel, Switzerland, 2009; pp. 7-43

5. Tang, G.; Russell, R.M. Carotenoids as provitamin A. In Carotenoids Volume 5: Nutrition and Health; Britton, G., Liaaen-Jensen, S., Pfander, H., Eds; Birkhauser Verlag: Basel, Switzerland, $2009 ; 149-172$.

6. Thibodeux, C.J.; Liu, H.W. Unraveling the mechanisms of isoprenoid biosynthetic enzymes: Mechanistic studies of the early stage enzymes. Chimia 2009, 63, 334-339.

7. Karrer, P.; Morf, R. Pflanzenfarbstoffe XXXV. Zur Konstitution des $\beta$-Carotins und $\beta$-Dihydrocarotins. Helv. Chim. Acta 1931, 14, 1033-1036.

8. Karrer, P.; Morf, R.; Schoepp, K. Zur Kenntnis des Vitamins A aus Fischtranen. Helv. Chim. Acta 1931, 14, 1431-1436.

9. Moore, T. The Relation of carotin to vitamin A. Lancet 1929, 2, 380-381.

10. Morton, R.A. Chemical aspects of the visual process. Nature 1944, 153, 69-71.

11. Oroshnik, W. The synthesis and configuration of neo-b vitamin A and neoretinene b. J. Am. Chem. Soc. 1956, 78, 2651-2652.

12. DeGrip, W.J.; Rothschild, K.J. Structure and mechanism of vertebrate visual pigments. In Molecular Mechanisms in Visual Transduction; Stavenga, D.G., DeGrip, W.J., Pugh, E.N., Jr., Eds.; Elsevier: Amsterdam, The Netherland, 2000; Vololume 3, pp. 1-54.

13. Van Wijk, A.A.C.; van de Weerd, M.B.; Lugtenburg, J. Synthetic scheme for the preparation of ${ }^{13} \mathrm{C}$-labeled 3,4-didehydroretinal, 3-hydroxyretinal and 4-hydroxyretinal up to uniform ${ }^{13} \mathrm{C}$ enrichment. Eur. J. Org. Chem. 2003, 863-868.

14. Gaertner, W. Invertebrate visual pigments, vision (I). In Molecular Mechanisms in Visual Transduction; Stavenga, D.G., DeGrip, W.J., Pugh, E.N., Jr., Eds.; Elsevier: Amsterdam, The Netherland, 2000; 297-388.

15. Rosenbaum, D.M.; Rasmussen, S.G.F.; Kobilka, B.K. The structure and function of G-proteincoupled receptors. Nature 2009, 459, 356-363.

16. Kono, M.; Goletz, P.W.; Crouch, R.K. 11-Cis- and all-trans-retinols can activate rod opsin: Rational design of the visual cycle. Biochemistry 2008, 47, 7567-7571. 
17. Mangeldorf, D.J.; Umesono, K.; Evans, R.M. The retinoid receptors. In The Retinoids: Biology, Chemistry, and Medicine; Sporn, M.B., Roberts, A.B., Goodman D.S., Eds.; Raven Press: New York, NY, USA, 1994; 319-349.

18. Buck, J.; Derguini, F.; Levi, E.; Nakanishi, K.; Hämmerling, U. Intracellular signaling by 14-hydroxy-4,14-retro-retinol. Science 1991, 254, 1654-1656.

19. Buck, J.; Grün, F.; Derguini, F.; Chen, Y.; Kimura, S.; Noy, N.; Hämmerling, U. Anhydroretinol: A naturally occurring inhibitor of lymphocyte physiology. J. Exp. Med. 1993, 178, 675-680.

20. Derguini, F.; Nakanishi, K.; Hämmerling, U.; Chua, R.; Eppinger, T.; Levi, E.; Buck, J. 13,14Dihydroxyretinol, a new bioactive retinol metabolite. J. Bio. Chem. 1995, 270, 18875-18880.

21. Moise, A.R.; Kuska, V.; Imanishi, Y.; Palczewshi, K. Identification of all-trans-retinol: All-trans13,14-dihydroretinol saturase. J. Biol. Chem. 2004, 279, 50230-50242.

22. Moise, A.R.; Domínguez, M.; Alvarez, S.; Alvarez, R.; Schupp, M.; Cristancho, A.G.; Kiser, P.D.; De Lera, A.R.; Lazar, M.A.; Palczewski, K. Stereospecificity of retinol saturase: Absolute configuration, synthesis, and biological evaluation of dihydroretinoids. J. Am. Chem. Soc. 2008, 130, 1154-1155.

23. Moise, A.R.; Kuska, V.; Blaner, W.S.; Baehr, W.; Palczewski, K. Metabolism and transactivation activity of 13,14-dihydroretinoic acid. J. Biol. Chem. 2005, 280, 27815-27825.

24. Olson, J.A. Recommended dietary intakes (RDI) of vitamin A in humans. Am. J. Clin. Nutr. 1987, 45, 704-716.

25. Ubels, J.L.; Macrae, S.M. Vitamin A is present as retinol in the tears of humans and rabbits. Curr. Eye Res. 1984, 3, 815-822.

26. Gasymov, O.K.; Abduragimov, A.R.; Yusifov, T.N.; Glasgow, B.J. Relaxation of ß-structure in tear lipocalin and enhancement of retinoid binding. Invest. Ophthalmol. Vis. Sci. 2002, 43, 3165-3173.

27. Underwood, B.A. Vitamin A in human nutrition: Public health considerations. In The Retinoids: Biology, Chemistry, and Medicine; Sporn, M.B., Roberts, A.B., Goodman D.S., Eds.; Raven Press: New York, NY, USA, 1994; pp. 211-227.

28. Billson, F.; Pararajasegaram, R. Prevention of childhood blindness. Based on the WHO Meeting on the Prevention of Childhood Blindness, London, UK, 29 May-1 June 1990; World Health Organization: Geneva, Switzerland, 1992.

29. Underwood, B.A.; Arthur, P. The contribution of vitamin A to public health. Faseb J. 1996, 10, 1040-1048.

30. Isler, O. History and industrial application of carotenoids and vitamin A. Pure Appl. Chem. 1979, $51,447-462$.

31. Reif, W.; Grassner, H. Die technische vitamin-A-synthese der BASF. Chem. Ing. Tech. 1973, 45, 646-652.

32. Paust, J. Recent progress in commercial retinoids and carotenoids. Pure Appl. Chem. 1991, 63, 45-58.

33. Isler, O.; Kienzle, F. Vitamin A. Kirk-Othmer Encyclopedia of Chemical Technology, 3rd ed.; John Wiley \& Sons: New York, NY, USA; Volume 24, pp. 140-158.

34. Schoenheimer, R. The Dynamic State of Body Constituents; Harvard University Press: Cambridge, USA, 1942. 
35. Kaegi, H.H. Synthesis of retinoids labeled with radioisotopes. In The Retinoids; Sporn, M.B., Roberts, A.B., Goodman, D.S., Eds.; Academic Press Inc.: San Diego, USA, 1984; Volume 1, $1147-1181$.

36. Olsen, J.A. Isotope-dilution techniques: A wave of the future in human nutrition. Am. J. Clin. Nutr. 1997, 66, 186-187.

37. Dueker, S.R.; Jones, A.D.; Smith, G.M.; Clifford, A.J. Stable isotope methods for the study of $\beta$-carotene- $\mathrm{d}_{8}$ metabolism in humans utilizing tandem mass spectrometry and high-performance liquid chromatography. Anal. Chem. 1994, 66, 4177-4185.

38. Tanumihardjo, S.A. Vitamin A status assessment in rats with ${ }^{13} \mathrm{C}_{4}$-retinyl acetate and gas chromatography/combustion/isotope ratio mass spectrometry. J. Nutr. 2000, 130, 2844-2849.

39. Wang, J.; Wang, Y.; Wang, Z.; Li, L.; Qin, J.; Lai, W.; Fu, Y.; Suter, P.M.; Russell, R.M.; Grusak, M. A.; Tang, G.; Yin, S. Vitamin A equivalence of spirulina $\beta$-carotene in Chinese adults as assessed by using a stable-isotope reference method. Am. J. Clin. Nutr. 2008, 87, 1730-1737.

40. Tang, G.; Qin, J.; Dolnikowski, G.G.; Russell, R.M.; Grusak, M.A. Golden rice is an effective source of vitamin A. Am. J. Clin. Nutr. 2009, 89, 1776-1783.

41. Mathies, R.A.; Lugtenburg, J. The primary photoreaction of rhodopsin. In Molecular Mechanisms in Visual Transduction; Stavenga, D.G., DeGrip, W.J., Pugh, E.N., Jr., Eds.; Elsevier: Amsterdam, The Netherland, 2000; Volume 3, 355-390.

42. Siebert, F.; Hildebrandt, P. Vibrational Spectroscopy in Life Science; WILEY-VCH Verlag gmbh \& Co. KGaA: Weinheim, Germany, 2008.

43. Sudo, Y.; Furutani, Y.; Wada, A.; Ito, M.; Kamo, N.; Kandori, H. Steric constraint in the primary photoproduct of an archaeal rhodopsin from regiospecific perturbation of C-D stretching vibration of the retinyl chromophore. J. Am. Chem. Soc. 2005, 127, 16036-16037.

44. Verhoeven, M.A.; Creemers, A.F.L. ; Bovee-Geurts, P.H.M.; DeGrip, W.J. ; Lugtenburg, J.; De Groot H.J.M. Ultra-high-field MAS NMR assay of a multispin labeled ligand bound to its G-protein receptor target in the natural membrane environment: Electronic structure of the retinylidene chromophore in rhodopsin. Biochemistry 2001, 40, 3282-3288.

45. Concistré, M.; Gansmüller, A.; McLean, N.; Johannessen, O.G.; Montesinos, I.M.; Bovee-Geurts, P.H.M.; Verdegem, P.; Lugtenburg, J.; Brown, R.C.D.; De Grip, W.J.; Levitt, M.H. Doublequantum ${ }^{13} \mathrm{C}$ nuclear magnetic resonance of bathorhodopsin, the first photointermediate in mammalian vision. J. Am. Chem. Soc. 2008, 130, 10490-10491.

46. Lansing, J.C.; Hohwy, M.; Jaroniec, C.P.; Creemers, A.F.L.; Lugtenburg, J.; Herzfeld, J.; Griffin, R.G. Determination of Torsion Angles in Membrane Proteins in Perspectives in Solid State NMR in Biology; Kiihne, S.R.; De Groot, H.J.M., Eds. Kluwer Academic Publishers: Dordrecht, The Netherlands, 2001; pp. 185-190.

47. Carravetta, M.; Edén, M.; Johannessen, O.G.; Luthman, H.; Verdegem, P.J.E.; Lugtenburg, J.; Sebald, A; Levitt, M.H. Estimation of carbon-carbon bond lengths and medium-range internuclear distances by solid-state nuclear magnetic resonance. J. Am. Chem. Soc. 2001, 123, 10628-10638.

48. Kiihne, S.R.; Creemers, A.F.L.; DeGrip, W.J.; Bovee-Geurts, P.H.M.; Lugtenburg, J.; De Groot, H.J.M. Selective Interface Detection: Mapping binding site contacts in membrane proteins by NMR Spectroscopy. J. Am. Chem. Soc. 2005, 127, 5734-5735. 
49. Venter, J.C.; Adams, M.D.; Myers, E. W.; Li, P.W.; Mural, R.J.; Sutton, G.G.; Smith, H.O.; Yandell, M.; Evans, C.A.; Holt, R.A. et al. The sequence of the human genome. Science 2001, 291, 1304-1351.

50. Murhammer, D.W. Review and patents and literature. The use of insect cell cultures for recombinant protein synthesis: Engineering aspects. Appl. Biochem. Biotechnol. 1991, 31, 283-310.

51. Vissers, P.M.A.M.; DeGrip, W.J. Functional expression of human cone pigments using recombinant baculovirus: Compatibility with histidine tagging and evidence for $N$-glycosylation. FEBS Lett. 1996, 396, 26-30.

52. Creemers, A.F.L.; Lugtenburg, J. The preparation of all-trans uniformly ${ }^{13} \mathrm{C}$-labeled retinal via a modular total organic synthetic strategy. Emerging central contribution of organic synthesis toward the structure and function study with atomic resolution in protein research. J. Am. Chem. Soc. 2002, 124, 6324-6334.

53. Lockhart, I.M. Isotopes: Essential Chemistry and Applications; Elvidge, J.A., Jones, J.R., Eds.; The Chemical Society: London, UK, 1979.

54. Torres, J.; Adams, P.D.; Arkin, I.T. Use of a new label, ${ }^{13} \mathrm{C}={ }^{18} \mathrm{O}$, in the determination of a structural model of phospholamban in a lipid bilayer. Spatial restraints resolve the ambiguity arising from interpretations of mutagenesis data. J. Mol. Biol. 2000, 300, 677-685.

55. Eyring, G.; Curry, B.; Broek, A.; Lugtenburg, J.; Mathies, R.A. Assignment and interpretation of hydrogen out-of-plane vibrations in the resonance Raman spectra of rhodopsin and bathorhodopsin. Biochemistry 1982, 21, 384-393.

56. Verdegem, P.J.E.; Bovee-Geurts, P.H.M.; DeGrip, W.J.; Lugtenburg, J.; De Groot, H.J.M. Retinylidene ligand structure in bovine rhodopsin, metarhodopsin-I, and 10-methylrhodopsin from internuclear distance measurements using ${ }^{13} \mathrm{C}$-labeling and 1-D rotational resonance MAS NMR. Biochemistry 1999, 38, 11316-11324.

57. DeLange, F.; Bovee-Geurts, P.H.M.; VanOostrum, J.; Portier, M.D.; Verdegem, P.J.E.; Lugtenburg, J.; DeGrip, W.J. An additional methyl group at the 10-position of retinal dramatically slows down the kinetics of the rhodopsin photocascade. Biochemistry 1998, 37, 1411-1420.

58. Winkler, F.J.; Kühnl, K.; Medina, R.; Schwarz Kaske, R.; Schmidt, H.L. Principles and Results of stable isotope labelling of L- $\alpha$-aminoacids by combined chemical and enzymatic methods. Isot. Environ. Health Stud. 1995, 31, 161-190.

59. Wald, G. The molecular basis of visual excitation. Nature 1968, 219, 800-807.

60. Durston, A.J.; Van der Wees, J.; Pijnappel, W.W.M.; Schilthuis, J.G.; Godsave, S.F. Retinoid signalling and axial patterning during early vertebrate embryogenesis. Cell. Mol. Life Sci. 1997, 53, 339-349.

61. Pijnappel, W.W.M.; Folkers, G.E.; De Jonge, W.J.; Verdegem, P.J.M.; De Laat, S.W.; Lugtenburg, J.; Hendriks, H.F.J.; Van der Saag, P.T.; Durston, A.J. Metabolism to a response pathway selective retinoid ligand during axial pattern formation. Proc. Natl. Acad. Sci. USA 1998, 95, 15424-15429.

62. Smith, S.O.; Palings, I.; Miley, M.E.; Courtin, J.; De Groot, H.J.M.; Lugtenburg, J.; Mathies, R.A.; Griffin, R.G. Solid-state NMR studies on the mechanism of the opsin shift in the visual pigment rhodopsin. Biochemistry 1990, 29, 8158-8164. 
63. Creemers, A.F.L.; Klaassen, C.H.W.; Bovee-Geurts, P.H.M.; Kelle, R.; Kragl, U.; Raap, J.; DeGrip, W.J.; Lugtenburg, J.; De Groot, H.J.M. Solid state ${ }^{15} \mathrm{~N}$ NMR evidence for a complex schiff base counterion in the visual G-protein-coupled receptor rhodopsin. Biochemistry 1999, 38, 7195-7199.

64. Baldwin, J.M.; Schertler, G.F.X.; Unger, V.M. An alpha-carbon template for the transmembrane helices in the rhodopsin family of G-protein-coupled receptors. J. Mol. Biol. 1997, 272, 144-164.

65. Ji, T.H.; Grossmann, M.; Ji, I. G-Protein-coupled receptors I. Diversity of receptor-ligand interactions. J. Biol. Chem. 1998, 273, 17299-17302.

66. Hubbart, R.; Kropf, A. The action of light on rhodopsin. Proc. Natl. Acad. Sci. 1958, 44, 130-139.

67. Palings, I.; Pardoen, J.A.; Van den Berg, E.M.M; Winkel, C.; Lugtenburg, J.; Mathies, R.A. Assignment of fingerprint vibrations in the resonance Raman spectra of rhodopsin, isorhodopsin, and bathorhodopsin: Implications for chromophore structure and environment. Biochemistry 1987, 26, 2544-2556.

68. Feng, X.; Verdegem, P.J.E.; Lee, Y.K.; Sandström, D.; Edén, M.; Bovee-Geurts, P.; DeGrip, W.J.; Lugtenburg, J.; De Groot, H.J.M.; Levitt, M.H. Direct determination of a molecular torsional angle in the membrane protein rhodopsin by solid-state NMR. J. Am. Chem. Soc. 1997, 119, 6853-6857.

69. Creemers, A.F.L.; Kiihne, S.; Bovee-Geurts, P.H.M.; DeGrip, W.J. ; Lugtenburg, J.; De Groot, H.J.M. ${ }^{1} \mathrm{H}$ and ${ }^{13} \mathrm{C}$ MAS NMR evidence for pronounced ligand-protein interactions involving the ionone ring of the retinylidene chromophore in rhodopsin. Proc. Natl. Acad. Sci.USA 2002, 99, 9101-9106.

70. Vissers, P.M.A.M.; Bovee-Geurts, P.H.M.; Portier, M.D.; Klaassen, C.H.W.; DeGrip, W.J. Large-scale production and purification of the human green cone pigment: Characterization of late photo-intermediates. Biochem. J. 1998, 330, 1201-1208.

71. Dawson, M.I.; Okamura, W.H. Chemistry and Biology of Synthetic Retinoids; CRC Press Inc.: Boca Raton, FL, USA; 1990.

72. Sporn, M.B.; Roberts, A.B.; Goodman D.S. Chemistry and physical properties of retinoids. In The Retinoids; Academic press, Inc.: Orlando, FL, USA, 1984; Volume 1, pp. 7-146.

73. Barnard, J.H.; Collings, J.C.; Whiting, A.; Przyborski, A.A.; Marder, T.B. Synthetic retinoids: Structure-activity relationships. Chem. Eur. J. 2009, 15, 11430-11442.

74. Sporn, M.B.; Roberts, A.B.; Goodman D.S. The Retinoids: Biology, Chemistry, and Medicine; Raven Press: New York, NY, USA, 1994.

75. Isler, O.; Huber, W. Ronco, A., Kofler, M. Synthese des vitamin A. Helv. Chim. Acta 1947, 30, 1911-1927.

76. Schwieter, U.; Planta, C.V.; Rüegg, R.; Isler,O. Synthesen in der Vitamen-A2-Reihe. Die darstellung von sterisch ungehinderten vitamin- $\mathrm{A}_{2}$-isomeren. Helv. Chim. Acta. 1962, 45, $528-541$.

77. Saucy, G.; Marbet, R. Über die reaktion von tertiären vinylcarbinolen mit isopropenyläther eine neue methode zur herstellung von $\gamma, \delta$,-ungesättigten ketonen. Helv. Chim. Acta 1967, 50, 2091-2095. 
78. Saucy, G.; Marbet, R. Über eine neuartige synthese von $\beta$-ketoallenen durch reaktion von tertiären acetylencarbinolen mit vinyläthern eine ergiebige methode zur herstellung des pseudojonons und verwandter verbindungen. Helv. Chim. Acta. 1967, 50, 1158-1167.

79. Kildahl-Andersen, G.; Konovalova, T.A.; Focsan, A.L.; Kispert, L.D.; Anthonsen, T.; LiaaenJensen, S. Comparative studies on radical cation formation from carotenoids and retinoids. Tetrahedron Lett. 2007, 48, 8196-8199.

80. Pommer, H. Synthesen in der vitamin-A-reihe. Angew. Chem. 1960, 72, 811-819.

81. Reif, W.; Grassner, H. Die technische vitamin A synthese der BASF. Chem. Ing. Tech. 1975, 45, 646-652.

82. Paust, J. Recent progress in commercial retinoids and carotenoids. Pure Appl. Chem. 1991, 63, $45-58$.

83. Ho, T.L. Hard and Soft Acid and Base Principle and Organic Chemistry; Academic Press: New York, NY, USA, 1977.

84. Rigassi, N.; Schweitzer, U. Process for the manufacture of polyene compounds. Patent CA 914201 (A), 07 November 1972.

85. Fransen, M.R.; Palings, I.; Lugtenburg, J.; Jansen, P.A.A.; Gronendijk, G.W.T. Preparation and photolysis of deuterium labeled rhodopsin. Recl. Trav. Chim. Pays-Bas. 1980, 99, 384-391.

86. Broek, A.D.; Lugtenburg, J. 10-Mono-, 11-mono-, 22-mono- and 11,12-dideutero retinal. Recl. Trav. Chim. Pays-Bas. 1981, 99, 363-366.

87. Broek, A.D.; Lugtenburg, J. Preparation of deuterium labeled retinals having high deuterium content on specific positions 10-mono-, 11-mono-, 10, 11-di- and 14,20,20,20-tetradeutero retinal. Recl. Trav. Chim. Pays-Bas. 1982, 101, 103-105.

88. Pardoen, J.A.; Winkel, C.; Mulder, P.P.J.; Lugtenburg, J. Synthesis of retinals labelled at positions 14 and 15 with ${ }^{13} \mathrm{C}$ and/or ${ }^{2} \mathrm{H}$. Recl. Trav. Chim. Pays-Bas. 1984, 103, 135-141.

89. Pardoen, J.A.; Neijenesch, H.N.; Mulder, P.P.J.; Lugtenburg, J. Synthesis of 10-, 11-, 14- and 20mono ${ }^{13}$ C-retinal. Recl. Trav. Chim. Pays-Bas. 1983, 102, 341-347.

90. Pardoen, J.A.; Van den Berg, E.M.M.; Mulder, P.P.J.; Lugtenburg, J. Synthesis of 8-, 9-, 12- and 13-mono ${ }^{13}$ C-retinal. Can. J. Chem. 1985, 63, 1431-1435.

91. Gebhard, R.; Courtin, J.M.L.; Shadid, L.B.; Van Haveren, C.J.; Van Haeringen, C.J.; Lugtenburg, J. Synthesis of retinals labelled with ${ }^{13} \mathrm{C}$ in the cyclohexene ring. Recl. Trav. Chim. Pays-Bas. 1989, 108, 207-214.

92. Courtin, J.M.L.; 't Lam, A.J.M.; Peters, A.J.M.; Lugtenburg, J. Synthesis of 5-,6-,7- and 18-mono ${ }^{13} \mathrm{C}$ labelled retinals. Recl. Trav. Chim. Pays-Bas. 1985, 104, 281-288.

93. Wang, Y.; Woo, W.S.; Van der Hoef, I.; Lugtenburg, J. 9-Demethyl-9-haloretinals by Wadsworth-Emmons Coupling- Easy preparation of pure (all-E), (9Z) and (11Z) isomers Eur. J. Org. Chem. 2004, 2166-2175.

94. Corey, E.J.; Erickson, B.W. $\gamma$-Condensation of an allylic phosphonium ylide. J. Org. Chem. 1974, $39,821-825$.

95. Still, W.C.; Gennari, C. Direct synthesis of Z-unsaturated esters. A useful modification of the Horner-Emmons olefination. Tetrahedron Lett. 1983, 24, 4405-4408.

96. Ando, K. Z-Selective Horner-Wadsworth-Emmons reaction of $\alpha$-substituted ethyl (diarylphosphono)acetates with aldehydes. J. Org. Chem. 1998, 63, 8411-8416. 
97. Ando, K.A. Mechanistic study of the Horner-Wadsworth-Emmons reaction: Computational investigation on the reaction pass and the stereochemistry in the reaction of lithium enolate derived from trimethyl phosphonoacetate with acetaldehyde. J. Org. Chem., 1999, 64, 6815-6821.

98. Mead, D.; Asato, A.E.; Denny, M.; Liu, R.S.H.; Hanzawa, Y.; Taguchi, T.; Yamada, A.; Kobayashi, N.; Hosoda, A.; Kobayashi, Y. 9-Cis 11-cis isomers of 18,18,18-, 19,19,19- and 20,20,20-trifluororetinal. Tetrahedron Lett. 1987, 28, 259-262.

99. Trehan, A.; Liu, R.S.H. All-cis-retinal and 7-cis,9-cis,11-cis-retinal. Tetrahedron Lett. 1988, 29, 419-422.

100. Wada A.; Wang F.; Ito M. A convenient and stereoselective synthesis of 11Z-3,4-didehydroretinal by Horner-Emmons reaction using diphenyl phosphonate. Chem. Pharm. Bull. 2008, 56, 112-114.

101. DeGrip, W.J.; Bovee-Geurts, P.H.M.; Van der Hoef, I.; Lugtenburg, J. 7,8 -Dihydro retinals outperform the native retinals in conferring photosensitivity to visual opsin. J. Am. Chem. Soc. 2007, 129 13265-13269.

102. Dawadi, P.B.S.; Lugtenburg, J. Efficient preparation of $\left[2-{ }^{13} \mathrm{C}\right]-$ and $\left[3-{ }^{13} \mathrm{C}\right]-3-\mathrm{cyano}-4-\mathrm{methyl}-3-$ pyrrolin-2-one. Eur. J. Org. Chem. 2007, 1294-1300.

103. Büchi, G.; Wuest, H. Synthetic studies on damascenones. Helv. Chim. Acta. 1971, 54, 17671776.

104. Kok, J.G.J.; Van Moorselaar, R. Technische synthese von vitamin A. Chem. Weekbl. 1973, 69, V8-V9.

105. Verdegem, P.J.E.; Monnee, M.C.F.; Lugtenburg, J. Simple and efficient preparation of [10,20$\left.{ }^{13} \mathrm{C}_{2}\right]$ - and $\left[10-\mathrm{CH}_{3}, 13-{ }^{13} \mathrm{C}_{2}\right]-10$-methylretinal: Introduction of substituents at the 2-position of 2,3-unsaturated nitriles. J. Org. Chem. 2001, 66, 1269-1282.

106. Wang, Y.; Lugtenburg, J. Preparation of (all-E)- and (11Z)-12-haloretinals and (11Z,13Z)- and (13Z)-14-haloretinals by the $\mathrm{C} 15+\mathrm{C} 5$ route - exploring the possibility of preparing any retinoid rationally chemically modified at any position in the conjugated tail. Eur. J. Org. Chem. 2004, 5100-5110.

107. Verhoeven, M.A.; Bovee-Geurts, P.H.M.; De Groot, H.J.M.; Lugtenburg, J.; DeGrip, W.J. Methyl substituents at the 11 or 12 position of retinal profoundly and differentially affect photochemistry and signalling activity of rhodopsin. J. Mol. Biol. 2006, 363, 98-113.

108. Freeman, J.P. Conjugate addition of the Wittig reagent. J. Org. Chem. 1966, 31, 538-541.

109. Bohlmann, F.; Zdero, C. Eine neue synthese von Cyclohexadien-Derivaten. Chem. Ber. 1973, 106, 3779-3787.

110. Dauben, W.G.; Hart, D.J.; Ipaktschi, J.; Kozikowski, A.P. A facile synthesis of substituted conjugated cyclohexadienes. Tetrahedron Lett. 1973, 4425-4428.

111. Dauben, W.G.; Ipaktschi, J. Facile synthesis of strained bridgehead olefins via the intramolecular Wittig reaction. J. Am. Chem. Soc. 1973, 5088-5089.

112. Padwa, A.; Brodsky, L. Utilization of the 1,4-conjugated Wittig reaction for the synthesis of substituted 1,3-cyclohexadines. J. Org. Chem. 1974, 39, 1318-1320.

113. Wang, Y.; Lugtenburg, J. 4,5-Didehydro-9-demethyl-9-halo-5,6-dihydroretinals and their 9cyclopropyl and 9-isopropyl derivatives- Simple preparation of $\alpha$-ionone derivatives and pure (allE)-, (9Z)- and (11Z)- $\alpha$-retinals. Eur. J. Org. Chem. 2004, 3497-3510. 
114. Sharma, A.S. On the regiochemistry of the reaction of lithioketeneimines with chlorotrimethylsilane. Ind. J. Chem. 1979, 18B, 84-86.

115. Al-Badri, H.; About-Jaudet, E.; Collignon, N. New and efficient synthesis of (E)-4diethoxyphosphonyl-2-methyl-2-butenal and of ethyl (E)-4-diethoxyphosphonyl-2-methyl-2butenoate, important building blocks in retinoid chemistry. Tetrahedron Lett. 1995, 36, 393-396.

116. Courtin, J.M.L.; Verhagen, L.; Biesheuvel, P.L.; Lugtenburg, J.; Van der Bend, R.L.; Van Dam, K. Bacteriorhodopsin, the influence of cyclohexene-ring methyls. Recl. Trav. Chim. Pays-Bas. 1987, 106, 112-119.

117. Spijker-Assink, M.B.; Winkel, C.; Baldwin, G.S.; Lugtenburg, J. 5-Demethylretinal and its 5- ${ }^{2} \mathrm{H}-$, $7-{ }^{2} \mathrm{H}-, 5,7-{ }^{2} \mathrm{H}_{2}$-isotopomers, synthesis, photochemistry and spectroscopy. Recl. Trav. Chim. PaysBas. 1988, 107, 125-131.

118. Groesbeek, M.; Lugtenburg, J. Synthesis of nitroxide containing polyenes: Two commercially modified retinals and their interaction with bacetriorhodopsin. Recl. Trav. Chim. Pays-Bas. 1995, 114, 403-409.

119. Van der Steen, R.; Biesheuvel, P.L.; Erkelens, C.; Mathies, R.A.; Lugtenburg, J. 8,16- and 8,18Methanobacteriorhodopsin synthesis and spectroscopy of 8,16- and 8,18-methanoretinals and their interaction with bacteriopsin. Recl. Trav. Chim. Pays-Bas. 1989, 108, 83-93.

120. Spijker-Assink, M.B.; Robijn, G.W.; Ippel, J.H.; Lugtenburg, J.; Groen, B.H.; Van Dam, K. (1R)and (1S)-5-Dethyl-8,16-methanobacteriorhodopsin and its properties. The synthesis and spectroscopy of 5-demethyl-8,16-methanoretinal in optically active and isotopic forms. Recl. Trav. Chim. Pays-Bas. 1992, 111, 29-40.

121. Groesbeek, M.; Van Galen, A.J.J.; Ippel, J.H.; Berden, J.A.; Lugtenburg, J. Three bacteriorhodopsin with ring-didemethylated 6-s locked chromophores and their properties. Recl. Trav. Chim. Pays-Bas. 1993, 112, 237-246.

122. Groesbeek, M.; Robijn, G.W.; Lugtenburg, J. Synthesis and spectroscopic characterization of the double locked $9 E, 11 Z$ retinal model systems $7 E, 13 E-11.19-10.20$-dimethanoretinal and its $13 Z$ isomer. Recl. Trav. Chim. Pays-Bas. 1992, 111, 92-98.

123. Groesbeek, M.; Kirillova, Y.J.; Boeff, R.; Lugtenburg, J. Syntheis of six novel retinals and their interaction with bacteriorhodopsin. Recl. Trav. Chim. Pays-Bas. 1994, 113, 45-52.

124. Van Amsterdam, L.J.P.; Lugtenburg, J. Total synthesis of a 10,14-sulphur-bridged 11-cis retinal analogue: 6-formyl-2-[4-(2,6,6-trimethylcyclohex-1-en-1yl)but-3-en-2-ylidene]-2H-thiopyran. $J$. Chem. Soc. Chem. Commun. 1982, 946-957.

125. Muradin-Szweykowska, M.; Peters, A.J.M.; Lugtenburg, J. The interaction of bacteriorhodopsin with 11,14-bridged retinals. The synthesis of 13-demethyl-11,14-imino-, 13-demethyl- $N$-methyl11,14-imino-, 13-demethyl-11,14-thio-, 13-demethyl-11,14-etheno and their binding with the baceteriopsin. Recl. Trav. Chim. Pays-Bas. 1984, 103, 105-109.

126. Broek, A.D.; Muradin-Szweykowska, M.; Courtin, J.M.L.; Lugtenburg, J. Preparation of 11,14 epoxy-bridged and isomeric chain demethylated retinals. 9-demethyl-, 13-demethyl-, and 9,13bisdemethyl retinals. Recl. Trav. Chim. Pays-Bas. 1983, 102, 46-51. 
127. Van den Berg, E.M.M.; Van der Bent, A.; Lugtenburg, J. Synthesis of specifically deuterated 9and 13-demethyl retinals. Recl. Trav. Chim. Pays-Bas. 1990, 109, 160-167.

Sample Availability: Samples of the compounds are available from authors.

(C) 2010 by the authors; licensee Molecular Diversity Preservation International, Basel, Switzerland. This article is an open-access article distributed under the terms and conditions of the Creative Commons Attribution license (http://creativecommons.org/licenses/by/3.0/). 